Florida International University FIU Digital Commons

FIU Electronic Theses and Dissertations

University Graduate School

6-30-2011

\title{
A Q Factor Analysis of College Undergraduate Students' Study Behaviors
}

Yang Yang

Florida International University, yyang001@fiu.edu

DOI: $10.25148 /$ etd.FI1 1080301

Follow this and additional works at: https://digitalcommons.fiu.edu/etd

\section{Recommended Citation}

Yang, Yang, "A Q Factor Analysis of College Undergraduate Students' Study Behaviors" (2011). FIU Electronic Theses and Dissertations. 449.

https://digitalcommons.fiu.edu/etd/449

This work is brought to you for free and open access by the University Graduate School at FIU Digital Commons. It has been accepted for inclusion in FIU Electronic Theses and Dissertations by an authorized administrator of FIU Digital Commons. For more information, please contact dcc@fiu.edu. 


\section{FLORIDA INTERNATIONAL UNIVERSITY}

Miami, Florida

\section{A Q FACTOR ANALYSIS OF COLLEGE UNDERGRADUATE STUDENTS' STUDY BEHAVIORS}

A dissertation submitted in partial fulfillment of the

requirements for the degree of

DOCTOR OF PHILOSOPHY

in

CURRICULUM and INSTRUCTION

by

Yang Yang

2011 
To: Dean Delia C. Garcia

College of Education

This dissertation, written by Yang Yang, and entitled A Q Factor Analysis of College Undergraduate Students' Study Behaviors, having been approved in respect to style and intellectual content, is referred to you for judgment.

We have read this dissertation and recommend that it be approved.

Laura Dinehart

Mohammed Farouk

Thomas Reio, Jr.

Leonard Bliss, Major Professor

Date of Defense: June 30, 2011

The dissertation of Yang Yang is approved.

\begin{tabular}{r}
$\begin{array}{r}\text { Dean Delia C. Garcia } \\
\text { College of Education }\end{array}$ \\
\hline Interim Dean Kevin O'Shea \\
University Graduate School
\end{tabular}

Florida International University, 2011 


\section{DEDICATION}

I dedicate this dissertation to my parents for their unconditional love, care, and support. Right after I received my Bachelor degree, they decided to send me overseas to further my education - the decision that will change the rest of my life. They believed it was time for their only child to explore the world and improve herself. They made that decision because of their courage, their farsightedness, and their high expectation and undoubted faith in me. They live halfway around the world, but they have been always with me during my years abroad. They make me who I am today. Without them, none of these would have been possible. Thank you. I love you forever.

献词

谨将此文奉献给我的父母。感谢他们无条件的爱和养育之恩。在我本科毕业后, 他们做出了改变我一生的决定一一送我到海外深造。因为他们的勇气, 远见, 对我 的期望和不曾动摇的信心, 他们相信应该让我去探索世界, 完善自我了。在我旅居 海外的岁月里，他们虽然住在地球的另一端，但他们始终伴随着我。是他们造就了 今天的我。没有他们, 我现在的一切都不可能。谢谢你们。我永远爱你们。 


\section{ACKNOWLEDGMENTS}

I would like to first sincerely thank my committee members, Dr. Laura Dinehart, Dr. Mohammed Farouk, and Dr. Thomas Reio for their valuable ideas and suggestions, and overall guidance and encouragement through this process.

I am also greatly indebted to Dr. Linda Bliss and Dr. Isadore Newman. They both provided their support, expertise, and insight to assist me in completing this dissertation. I thank them for everything they have done for me. They have made this process much smoother.

Dr. Susan Ramlo from University of Akron deserves special thanks for lending her expertise in Q method. The Q listserv community also deserves special recognition for helping me, a novice Q researcher, become familiar with this fascinating Q method.

Finally, I want to extend my deepest appreciation to my dissertation chair, Dr.

Leonard Bliss. I am very grateful to have met him and had him as my dissertation chair. During our ongoing interaction, he has become a respectable mentor, knowledgeable colleague, and a dear friend. He guided me to understand, appreciate, and enjoy this journey, which could be otherwise overwhelming. More importantly, his challenging and encouragement has led to my personal growth, which goes far beyond academics. My gratitude to you is truly beyond words. 


\title{
ABSTRACT OF THE DISSERTATION \\ A Q FACTOR ANALYSIS OF COLLEGE UNDERGRADUATE STUDENTS' \\ STUDY BEHAVIORS
}

\author{
by \\ Yang Yang \\ Florida International University, 2011 \\ Miami, Florida \\ Professor Leonard Bliss, Major Professor
}

The purpose of this study was to better understand the study behaviors and habits of university undergraduate students. It was designed to determine whether undergraduate students could be grouped based on their self-reported study behaviors and if any grouping system could be determined, whether group membership was related to students' academic achievement.

A total of 152 undergraduate students voluntarily participated in the current study by completing the Study Behavior Inventory instrument. All participants were enrolled in fall semester of 2010 at Florida International University. The Q factor analysis technique using principal components extraction and a varimax rotation was used in order to examine the participants in relation to each other and to detect a pattern of intercorrelations among participants based on their self-reported study behaviors. 
The Q factor analysis yielded a two factor structure representing two distinct student types among participants regarding their study behaviors. The first student type (i.e., Factor 1) describes proactive learners who organize both their study materials and study time well. Type 1 students are labeled "Proactive Learners with Well-Organized Study Behaviors". The second type (i.e., Factor 2) represents students who are poorly organized as well as being very likely to procrastinate. Type 2 students are labeled Disorganized Procrastinators.

Hierarchical linear regression was employed to examine the relationship between student type and academic achievement as measured by current grade point averages (GPAs). The results showed significant differences in GPAs between Type 1 and Type 2 students at the .05 significance level. Furthermore, student type was found to be a significant predictor of academic achievement beyond and above students' attribute variables including sex, age, major, and enrollment status. The study has several implications for educational researchers, practitioners, and policy makers in terms of improving college students' learning behaviors and outcomes. 


\section{TABLE OF CONTENTS}

CHAPTER

PAGE

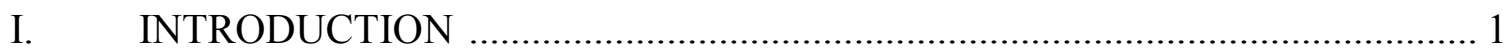

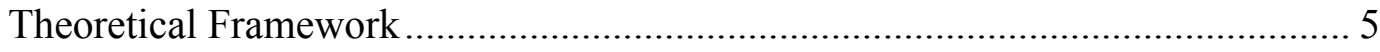

Purpose of the Study …………………....................................................... 8

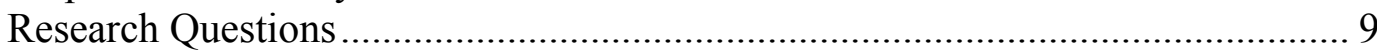

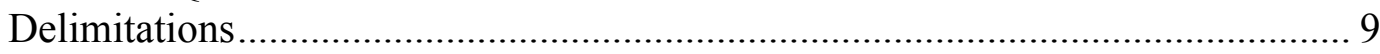

Operational Definition of terms ...................................................................... 9

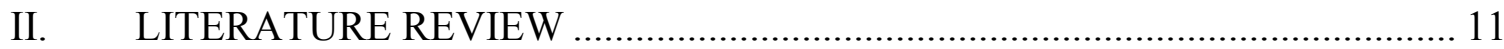

Study Behaviors and Self-Regulated Learning ................................................... 11

Q Methodology and Q Factor Analysis ............................................................... 45

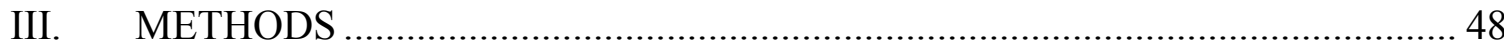

Research Design and Rationale .................................................................... 48

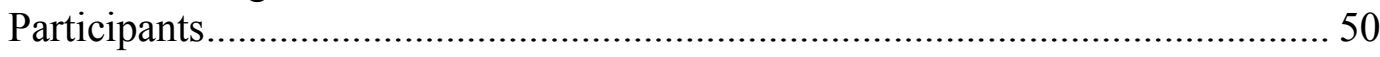

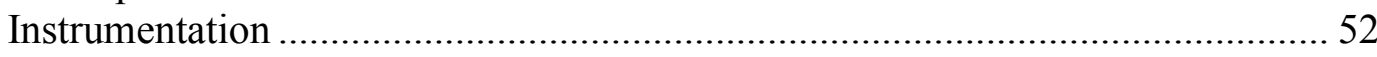

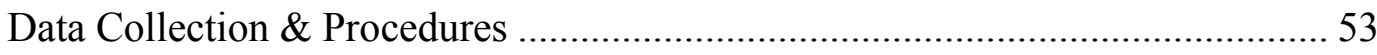

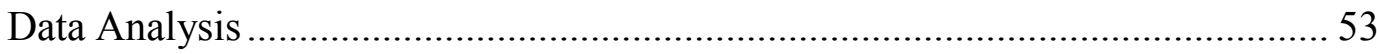

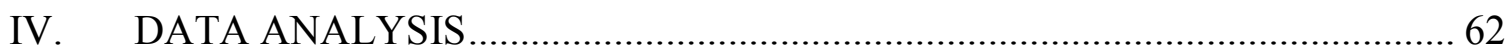

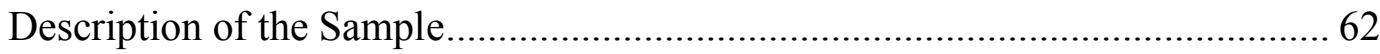

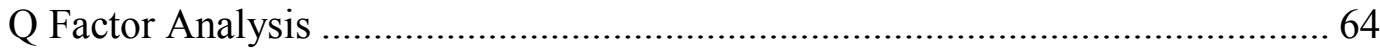

Correlation of Study Behavior Types with Academic Achievement...................... 76

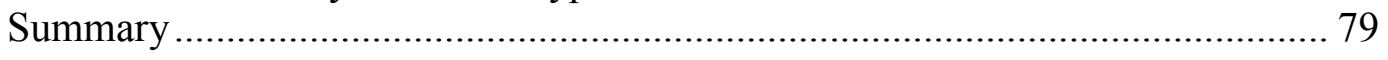

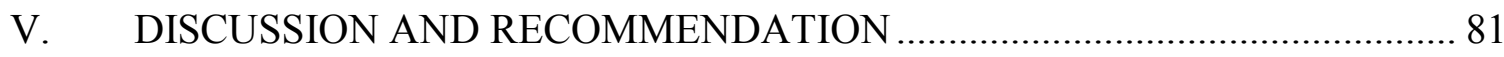

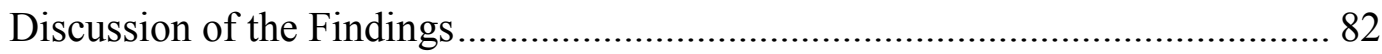

Recommendations for Future Research and Practice ........................................ 91

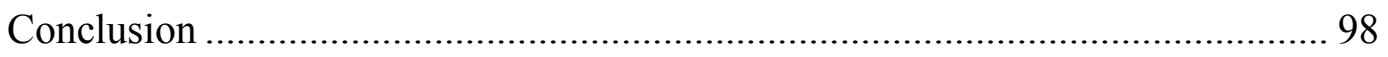

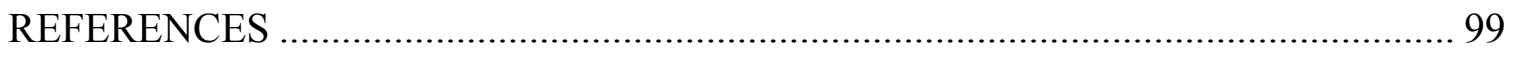

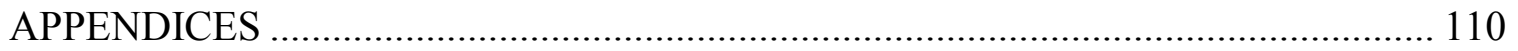

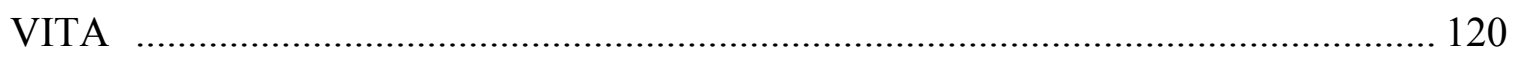




\section{LIST OF TABLES}

TABLE

PAGE

1. Example: Array of z-scores for Each Factor Type.

2. Participant Characteristics by Sex

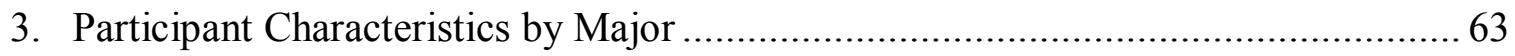

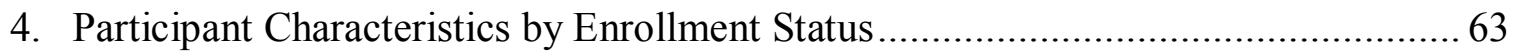

5. Two-Factor Solution With Number of Defining Respondents .............................. 65

6. Factor 1 Extreme Statements With High and Low z-scores ................................ 70

7. Factor 2 Extreme Statements With High and Low z-scores .............................. 71

8. Distinguishing Statements for Factor 1 and Factor 2 (or

Descending Array of Difference Between Factor 1 and Factor 2)......................... 73

9. Consensus Statements for Factor 1 and Factor 2 ........................................... 75

10. $\mathrm{t}$-Test for Differences in GPA by Student Type .............................................. 77

11. Hierarchical Multiple Regression Analyses Predicting GPA From

Student type, Sex, Age, Major, and Enrollment Status ....................................... 79 


\section{CHAPTER I}

\section{INTRODUCTION}

As more and more students enter institutions of higher education in the United States, the number of students who are academically underprepared for college-level work is increasing (National Center for Education Statistics, 2004a). Such lack of readiness to achieve at the college level leads to an overall high rate of attrition (National Center for Education Statistics, 2004b). This is because students who are academically unprepared must do remedial work and this increases their time to graduation. Students who have enrolled in college for long periods of time are less likely to graduate than other students. It is, therefore, not surprising that the graduation rate of the U.S. higher institutions is decreasing (National Center for Education Statistics, 2004b).

Educators and educational researchers have tried to deal with this problem by looking at the factors that may impact students' academic attainment. For example, one of the most frequently mentioned factors is prior knowledge of specific subject content, which is often demonstrated by previous performance in the content area. Another important factor is not limited to any specific subject area, but may facilitate the acquisition of content knowledge. That is the typical behaviors and habits students exhibit when they are studying (Bliss \& Sandiford, 2004; Zimmerman, 1989). 
Appropriate study behaviors are believed to contribute to students' academic success in colleges (Bandura, 2001; Zimmerman, 2008).

Study behaviors demonstrate students' concepts of how to accomplish learning goals and the specific actions taken to reach such goals (Jones, Slate, Perez, \& Marini, 1996). Related to this definition, the difference between study behaviors and study skills was explicitly addressed by Bliss and Mueller $(1987,1993)$ when they investigated the association between appropriate study behaviors and academic achievement among college students. According to Bliss and Mueller, study skills refer to specific techniques that could be potentially used for learning. Yet without being fully understood and appropriately applied, study skills do not help learning very much. By contrast, study behaviors represent what students actually do when they are equipped with necessary skills. In other words, study behaviors require the knowledge of study skills, but more specifically focus on the actualization of these skills by students when they carry out academic tasks.

Understanding students' study behaviors and habits is especially important in the college environment compared with that in primary and secondary schools. College life is often characterized by flexibility and variety. All kinds of events are constantly happening, which could easily take up students' time, energy and attention. Besides, being an adult means having fewer rules and guidelines set by external sources, such as 
parents and teachers. Therefore, it is critical for college students to be able to discipline themselves. Furthermore, because of the low level of external guidance and assistance, students' self directing and monitoring of their actions when studying is very likely to impact their learning outcomes and, thus, their overall attainment in their college and university studies.

Research has consistently supported the idea that study behaviors are highly related to academic achievement (Schunk \& Zimmerman, 1994; Yumusak, Sungur, \& Cakiroglu, 2007). In addition, the appropriate use of study behaviors has demonstrated positive academic outcomes in various areas (Kitsantas, Winsler, \& Huie, 2008; Zimmerman \& Kitsantas, 1999). For example, using the Study Behavior Inventory Bliss and his colleagues (Bliss \& Mueller, 1993; Bliss \& Sandiford, 2004) consistently found three factors underlying study behaviors. These were feelings of academic self-efficacy, time management for long-term tasks, and time management for short-term tasks and each correlated highly with measures of academic achievement. Academic self-efficacy refers to learners' beliefs concerning their capabilities to accomplish academic tasks and activities (Bandura, 1977). Academic self-efficacy beliefs students hold help determine how they will actualize their study skills when completing academic tasks. Students with high self-efficacy are more likely to choose challenging tasks, work harder, persist longer, persevere when facing difficulties, and are more likely to succeed (Schraw, 
Crippen, \& Hartley, 2006). Study findings have supported the notion that academic self-efficacy is highly correlated with and predictive of learning outcomes in a broad range of settings (Kitsantas, 2002; Schraw et al., 2006; Schunk \& Zimmerman, 2006).

Time management refers to how well individuals are able to utilize and allocate time appropriately, which in turn, affects the accomplishment of their personal goals (Ogonor \& Nwadiani, 2006). Effective time management generally is positively related to students' performance; that is, students who are better at planning and managing their time are more likely to have higher achievement than students who manage time poorly (Bliss \& Mueller, 1993; Eilam \& Aharon, 2003; Ogonor \& Nwadiani, 2006).

Conversely, research also suggests that ineffective study behaviors can lead to underperformance or even academic withdrawal (Goldfinch \& Hughes, 2007). Specifically, students with low academic self-efficacy are likely to avoid difficult tasks, lack persistence, and easily give up when facing obstacles while studying (Niemczyk \& Savenye, 2001; Pajares, 2008). Similarly, those who manage time poorly are unable to allocate their time reasonably, pace their study appropriately, and often cram for classes until the last minute. Poor time management tends to yield unsatisfactory academic performance (Balduf, 2009). 
Clearly, study behaviors play a key role in students' academic outcomes. In order to improve students' academic success and thus the college graduation rate, there is a need to examine study behaviors closely.

\section{Theoretical Framework}

This study looked at study behaviors through the social cognitive model of self-regulated learning. Self-regulated learning is a particular application of self-regulation theory in academic settings. To begin with, self-regulation is a theory used to understand what individuals do as they perform a task successfully. The theory of self-regulation is heavily influenced by Bandura's (1977) work on social cognitive theory (Dinsmore, Alexander, \& Loughlin, 2008). Social cognitive theory is based on the idea that person, behavior, and environment are all key factors in influencing individuals' development and learning (Bandura, 1977). Bandura described human functioning as the interplay between person, behavior, and environment. He suggested that each of these three types of factors can influence another and will be in turn influenced by it (Schraw et al., 2006). According to social cognitive theory, learning is not an isolated action. Instead, the study behaviors learners execute are functions of their thinking patterns and personal beliefs as well as external environmental influences, all of which may affect their behaviors. 
Based on the triadic relationship of human functioning, Bandura (1986) considered self-regulation as the process that occurs within the reciprocal interrelationship of the person, the behavior, and the environment. Self-regulation refers to the thoughts, feelings, and actions individuals generate and adjust in response to changing conditions (Caprara \& Cervone, 2000; Zimmerman, 2000a). When applied in academic settings, self-regulated learning is considered to be a self-directive process that requires learners to direct and regulate their cognitive, motivational, and behavioral endeavors in order to accomplish academic goals (Zimmerman, 1998).

Numerous variables influence the nature of the learning process and its quality. Therefore, self-regulated learning includes multiple self-regulatory dimensions regulation of thinking, regulation of motivation, and regulation of behavior (Pintrich \& Zusho, 2007). Within the dimension of motivational regulation, academic self-efficacy is the most commonly mentioned factor (Pajares, 2008). While students may have the capability to use self-regulatory processes and strategies, they do not necessarily do so. This helps explain how the personal beliefs students hold would motivate them to apply such processes and behaviors in various academic situations. Academic self-efficacy involves students' judgments and beliefs concerning their capability to perform academic tasks (Bandura, 1997). Academic self-efficacy beliefs impact the way students 
approach tasks, the strategies they execute, and the adjustment they make as they proceed, all of which are tied to academic outcomes.

Similarly, time management is considered a typical component in the dimension of behavioral regulation (Pintrich \& Zusho, 2007). Managing and regulating their time usage requires students to balance the time and effort they spend on academic and non-academic activities, especially in the college environment where non-academic-related events could easily distract students. As they proceed in their academic tasks, students may realize the insufficiency (or overspending) of their effort and time and therefore adjust the time and effort devoted to the tasks based on their goals. Time management is believed to be positively associated with academic performance (Bliss \& Sandiford, 2004; Lahmers \& Zulauf, 2001; Young, Klemz, \& Murphy, 2003).

This study dealt with three particular factors underlying study habits - academic self-efficacy, time management for short-term tasks, and time management for long-term tasks. Serving as the theoretical framework, the social cognitive model of self-regulated learning theory suggests multidimensional self-regulatory processes are involved in academic learning. The theory recognizes the roles that multiple factors play in students' learning processes, among which are the motivational factor of academic self-efficacy and the behavioral factor of time management. Based on self-regulated 
learning theory, I expected that how well students managed their feelings of academic self-efficacy and time usage would predict their academic performance.

\section{Purpose of the Study}

This study was undertaken to better understand the study behaviors of college and university undergraduate students. Specifically, the study intended to determine how undergraduate students can be categorized based on their self-reported study behaviors and whether the categories of students can predict their academic achievement. A large body of literature has shown the positive relationship between students' use of appropriate study behaviors and their academic performance (Yumusak et al., 2007; Zimmerman \& Kitsantas, 1999). However few studies have attempted to categorize students based on the types of their study behaviors and make predictions concerning academic achievement based on these categorizations. This study attempted to produce a taxonomy composed of typologies of students that are based on their self-reported study behaviors and, after succeeding in that, to test the relationship between group membership and students' academic achievement. The study aimed to inform educators and practitioners about students' distinctive patterns of study behaviors and how the study behavior patterns were related to learning outcomes. By doing so, this study could lead to further research that may enable educators to adjust their pedagogical 
approaches and/or provide students with more appropriate learning strategies in order to improve their overall academic attainments.

\section{Research Questions}

The research questions were:

1. What are the typologies of undergraduate students that represent students' different patterns of study behaviors?

2. Is there a relationship between each typology and students' academic achievement as measured by current GPA?

\section{Delimitations}

This study was delimited to undergraduate students at Florida International University's Modesto Maidique Campus.

\section{Operational Definitions of Terms}

Academic achievement. Academic achievement was measured by students' current grade point averages.

Academic self-efficacy. Academic self-efficacy refers to learners' beliefs concerning their abilities to accomplish academic tasks and activities (Bandura, 1977). It was measured by the score on Factor I of the Study Behavior Inventory.

Short-term time management. Short-term time management refers to how well individuals are able to utilize and allocate time appropriately for recurring, routine tasks 
(Bliss \& Mueller, 1993). It was measured by the score of Factor II of the Study

Behavior Inventory.

Long-term time management. Long-term time management refers to how well

individuals are able to utilize and allocate time appropriately for long-term, specific,

nonrecurring tasks (Bliss \& Mueller, 1993). It was measured by the score on Factor III of the Study Behavior Inventory. 


\section{CHAPTER II}

\section{REVIEW OF THE LITERATURE}

The current study examined university students' study behaviors, determined whether students can be grouped based on their self-reported study behaviors, and investigated whether group membership is associated with students' academic achievement. Study behaviors were examined through the theoretical lens of self-regulated learning. In this chapter, I clarify self-regulated learning theory and discuss the relationship of self-regulated learning and academic achievement. Two factors of study behaviors, namely academic self-efficacy and time management, were of particular interest in the current study. These two factors were explained through the framework of self-regulated learning as well. Finally, in order to determine whether students can be classified on the basis of their study behaviors, Q factor analysis was employed as the data analysis technique. Q factor analysis is not widely utilized in the educational field, so I briefly introduce its goals and features in the final portion of this chapter.

\section{Study Behaviors and Self-Regulated Learning}

Study at the college and university level requires a great deal of independent work.

To succeed, students have to be aware of and manage their approaches to studying and to use study strategies well (Lindblom-Ylanne, 2004). In an effort to understand and 
describe what successful learners do as they learn, research on self-regulation of academic learning and performance has emerged as a prominent area of inquiry in the past few decades (Boekaerts, Pintrich, \& Zeidner, 2000; Zimmerman, 2000a). Several models (see Zimmerman, 2001) have been employed to understand the concept of self-regulation, among which Bandura's (1977) social cognitive model is the most influential.

\section{Social Cognitive Theory of Human Functioning}

Study concerning self-regulation has been heavily influenced by Bandura's (1977) work on social cognitive theory (Dinsmore, Alexander, \& Loughlin, 2008). Social cognitive theory (originally known as social learning theory) is a theory of human functioning. It is based on the idea that person, behavior, and environment are all key factors in influencing individuals' development and learning (Bandura, 1977). Bandura described human functioning as the triadic interaction between person, behavior, and environment (see Figure 1). Personal factors that affect behaviors include thoughts, beliefs and attitudes. Behavioral factors include the effects of prior performance and quality of the engagement in a task. Environmental factors involve access to information, external feedback, and help from other participants or from evaluators.

Bandura (1997) suggested that each of these three factors (personal, behavioral, and environmental) can influence another and will be in turn influenced by it. 
Specifically, how we think can affect what we do and how we perceive the environment; our behaviors can change our environment and influence how we think of ourselves; and the environment can affect how we think and what we do (Schraw, Crippen, \& Hartley, 2006). This notion of the triadic interaction can be specifically applied to understanding the nature of self-regulation (and self-regulated learning).

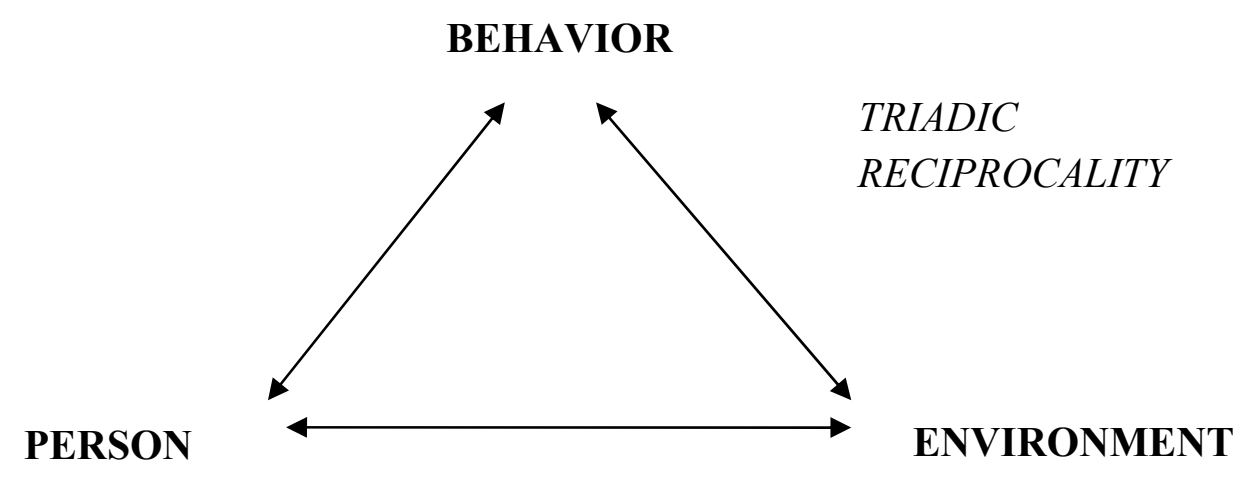

Figure 1. Model of the relations between the three types of factors in Bandura's (1986) conception of triadic reciprocity.

\section{The Social Cognitive Perspective of Self-Regulated Learning}

Bandura incorporated self-regulation when he emphasized the triadic reciprocality

of human functioning (1986). Specifically, he considered self-regulation as the process that occurs during the reciprocal interaction of the environment and the person, mediated through the behavior. From this perspective, self-regulation is defined as, "self-generated thoughts, feelings, and actions that are planned and cyclically adapted to 
the attainment of personal goals" (Zimmerman, 2000a, p.14). The social cognitive model of self-regulation not only focuses on the actions and skills necessary to manage one's environment, but also emphasizes the personal beliefs and characteristics needed to employ skills in relevant situations (Jakubowski \& Dembo, 2002). Therefore, a self-regulatory system includes regulation of one's thinking, behavior, and motivation while taking account of environmental factors as well.

When applied in academic settings, research on self-regulation of learning has tried to determine how students become masters of their own learning processes (Whipp \& Chiarelli, 2004). The increased focus of self-regulation research in the academic domain has directly contributed to the emergence of the phrase self-regulated learning. Self-regulated learning is defined as a self-directive process that requires learners to activate and sustain their motivational, behavioral, and cognitive learning endeavors in order to accomplish important and valuable academic goals (Zimmerman, 1998). Learners who successfully execute self-regulated learning are considered self-regulated learners. Again, from the social cognitive perspective, personal, behavioral, and environmental factors will interact with one another and thus impact students' learning processes.

Self-regulated learning is a particular application of self-regulation in academic settings and largely shares the same theoretical foundation with self-regulation. 
Therefore in the rest of this chapter I will discuss them together and use self-regulated learning, in particular, as an example when appropriate.

\section{Regulation of Cognition}

Self-regulation is an ongoing process that occurs during the interaction between the person, the behavior, and the environment. During this interaction, self-regulatory functioning involves several key subprocesses: planning, self-monitoring, self-evaluation, and self-reaction (Zimmerman, 1998; Zimmerman \& Bandura, 1994). Take academic learning as an example. When planning for a new academic task, students have to set task-specific goals that are used as criteria to guide their cognition in general (Pintrich \& Zusho, 2007). Based on the goals they set, students plan and select appropriate cognitive strategies and methods to complete the tasks (Zimmerman, 2000a). It is noteworthy that the strategies students use only involve cognitive functions, but the decision to select and use them requires a higher level of functioning known as "metacognition", which I will explain later.

Another self-regulatory process, self-monitoring, involves the awareness and monitoring of various aspects of cognition. The self-monitoring process requires students to pay attention to the ongoing cognitive processes they are engaged in. It also allows students to be aware of their progress towards the goals they set (Kanfer, 1971). For example, students may ask themselves whether they understand the mathematical 
concept they are studying or whether they comprehend the main idea of the last few paragraphs in a reading task. Self-monitoring is critical as it provides the foundation for self-evaluation (Pintrich \& Zusho, 2007).

Self-evaluation refers to applying personal goals or standards to judge one's performance (Zimmerman, 2000a). It involves controlling or changing the cognitive strategies learners are using and/or the cognitive processes they are engaged in. Learners evaluate the possible discrepancy between their ultimate goal and the progress they have made toward the learning goal based on the information collected from self-monitoring. By doing so, they adjust the cognitive strategies and processes they will use in the future to achieve their goals (Zimmerman, 1998, 2000a). Highly self-regulated learners evaluate themselves more often and make better adaptations than poorly self-regulated individuals (Zimmerman \& Kitsantas, 1997, 1999).

Furthermore, when learners engage in self-reaction, they generate responses to the outcomes of their performance, and the responses in turn guide and motivate future actions. Students who feel satisfied with their learning are more likely to be motivated to carry out similar behaviors and use similar strategies in future settings than those who are less satisfied. Additionally, when the performance outcomes fall short of desired goals, learners who attribute poor performances to strategy deficiency rather than to lack 
of ability are more likely to adopt more effective strategies and processes that serve their future learning better (Zimmerman \& Kitsantas 1999).

These self-regulatory actions students take to control their cognition are highly related to their learning quality and achievement (Schunk \& Zimmerman, 1994). A number of studies have looked at the role of self-regulatory processes in students' learning. For example, Zimmerman and Kitsantas (1997) examined the impact of goal setting during self-regulation on the acquisition of a complex motor skill - dart-throwingamong 90 ninth and tenth grade girls. Two types of goals were provided. The outcome goal focused on hitting the bull's eye on the target; whereas the process goal emphasized a multistep strategy for executing the throw. The girls who set process goals attained higher performance outcomes and expressed greater satisfaction than those who set product goals. More importantly, some girls started to pursue a process goal, and switched to a product goal once they could perform the steps automatically. The girls who shifted goals developmentally from process to outcome focus outperformed and indicated more positive self-reaction than those who adhered to only process goals or only outcome goals. Their study suggested that goal setting — as one of the critical self-regulatory processes of cognition — facilitates students' performance and leads to a positive self-reaction to the outcomes. 
Bringing the idea of the efficacy of different self-regulated learning processes carried out together, Pintrich and De Groot (1990) examined the relationship between multiple self-regulated learning processes and academic performance in science and English classes for 173 seventh graders. The results showed that the use of self-reported self-regulated learning strategies were predictors of performance. Higher levels of use of planning, comprehension monitoring, and organizing were associated with higher levels of achievement on all assignments that were measured, (i.e., seatwork, exams or quizzes, and essay reports) and resulted in higher final grades. Their study results support the idea that the engagement in self-regulated strategies and processes are directly tied to students' academic performance.

Whipp and Chiarelli (2004) added the notion of context when they explored how six successful students used self-regulated learning strategies to complete tasks and cope with challenges in a web-based technology course. The results of interviews and archived course documents indicated that these students used and adapted many metacognitive self-regulation strategies in the web-based learning environment. Participants were actively involved in planning, self-observation, organizing and transforming instructional materials, self-monitoring, and self-reflection throughout the semester. Their study suggests that while traditional classroom and web-based contexts may place different emphases on some self-regulatory strategies (e.g., help seeking) due 
to the environment, enacting and managing those strategies and processes to regulate students' cognition is indispensable in the pursuit of academic success.

Camahalan (2006) also examined the role of several subprocesses in the regulation of cognition as related to mathematics academic achievement among 60 fourth and sixth grade low-performers in the Philippines. After collecting the baseline scores on a mathematics achievement test and a self-regulated learning strategy use test, participating students were randomly placed into the experimental or the control group. The participants in the experimental group were given 6 consecutive weeks of training on self-regulated learning processes and strategies while the control group received no training. The self-regulatory processes included in the training were goal setting and planning, organizing, monitoring, and self-evaluation. After controlling the baseline data, the results of post-training assessment showed significant differences in both self-regulatory process usage and mathematics achievement between the experimental and the control group. After the training, almost all students in the experimental group had improved in their self-regulatory learning strategies and processes as well as their mathematics achievement. The results suggested that the critical processes and strategies students use to regulate their cognition help them take more control of their learning, which in turn, may contribute to higher academic achievement. 
In sum, planning, self-monitoring, self-evaluation, and self-reaction, as key self-regulatory processes, explain the ways through which individuals monitor and regulate the cognitive processes and strategies they use. They are all considered regulation of cognition in the framework of self-regulation (and self-regulated learning). Since I have been discussing individuals' monitoring and regulating of cognition, it is worth mentioning another related theory here - metacognition theory. Metacognition has been defined as “one's knowledge concerning one's own cognitive processes or anything related to them, e.g., the learning-relevant properties of information or data" (Flavell, 1976, p. 232). Metacognition is referred to as thinking about one's own thinking or cognition about cognition (Flavell, 1971), which reflects a higher level of thinking that involves control over the cognitive processes used in learning.

In order to explain how metacognition functions, theorists have divided metacognition into metacognitive knowledge and metacognitive regulation/control (Baker \& Brown, 1984; Flavell, 1979). Metacognitive knowledge refers to knowledge people acquired about their own cognitive processes (Flavell, 1979). Metacognitive regulation/control involves the processes that coordinate cognition. Such processes mainly include monitoring (e.g., error detection) and controlling (e.g., error correction, planning) one's cognition (Reder \& Schunn, 1996). 
To effectively regulate one's own cognition, an individual has to not only possess necessary metacognitive knowledge about his/her cognition, but also apply such knowledge to direct the cognitive processes and strategies s/he uses. For example, students know that they have difficulty with geometry (i.e., metacognitive knowledge); so in the upcoming mathematics examination, they decide they will answer the algebra questions first and save the geometry questions for last (i.e., metacognitive regulation/control). Metacognitive knowledge and metacognitive regulation/control are critical in one's learning process as they help to oversee learning and ensure the goal of learning has been met (Baker \& Brown, 1984).

Comparing the metacognitive regulation/control component of metacognition theory and the key self-regulatory processes of cognition mentioned above (i.e., planning, self-monitoring, self-evaluation, and self-reaction), it is clear that these processes describe how metacognition, particularly metacognitive regulation/control, functions in one's learning. Students who are successful at self-regulation tend to be more metacognitively controlled and thus better at regulating their studying and learning. Indeed, most self-regulation theorists (e.g., Pintrich \& Zusho, 2007; Schunk, 2008; Zimmerman, 2000a) have suggested that metacognition plays an important role in self-regulation, although the two theories also have distinctions. 
An important distinction is that the only focus of metacognition theory is regulating cognition while self-regulation theory and self-regulated learning focus on several factors. Specifically, in addition to regulation of cognition, self-regulation theory equally emphasizes regulation of motivation and behaviors.

\section{Regulation of Motivation}

Regulation of motivation refers to the control of motivational beliefs students have about themselves in relation to the tasks (Pintrich, 2000). As mentioned earlier, self-regulation (and self-regulated learning) is an ongoing and temporal process which students have to initiate proactively. It is one thing to be capable of utilizing self-regulatory processes and strategies but another thing to actually get students themselves to apply such processes and behaviors, resulting in appropriate study behaviors in various academic situations. Therefore, understanding these students' personal beliefs is important as they demonstrate the degree to which they are motivated or likely to initiate and maintain regulation of their own thinking and behaviors (Bandura, 1997; Pintrich \& Zusho, 2007).

The frequently mentioned motivational beliefs that are related to self-regulation (and self-regulated learning) include self-efficacy, task values, and outcome attributions. Self-efficacy is considered the most critical motivational factor in self-regulation (Schunk \& Zimmerman, 2006). 
Bandura (1977) introduced the concept of self-efficacy when he proposed social cognitive theory. Self-efficacy is defined as "the belief in one's capabilities to organize and execute courses of action required to produce given attainments" (Bandura, 1977, p. 3). It describes what individuals feel they can do rather than what they will do in a certain setting. Academic self-efficacy refers to learners' beliefs concerning their capabilities to accomplish academic tasks and activities. Students who believe they have necessary capabilities to execute an academic task are considered to have high academic self-efficacy; whereas those who believe they lack the required capabilities are seen as having low academic self-efficacy.

It is important to mention that self-efficacy is different from other self-related measures. Most self-related measures, such as self-concept, perceived self-control, etc., are concerned with personal qualities or characteristics. By contrast, self-efficacy is a measure that focuses on performance capabilities (Pajares, 1996, 2008). Specifically, self-efficacy indicates how individuals judge their capabilities to accomplish a given task, such as driving a truck, playing a musical instrument, or solving a mathematics problem, rather than who they are personally or how they feel about themselves in general. Related to this point, self-efficacy is a domain specific concept (Pajares, 2008). Unlike self-concept being a single broader disposition of self, self-efficacy differs in various 
domains (Pajares, 1996). One's efficacy beliefs about doing well academically could be very different from one's beliefs about one's social skills.

Self-efficacy lies at the center of Bandura's social cognitive theory of human functioning. As related to learning, academic self-efficacy involves how learners perceive themselves in terms of their abilities to accomplish an academic-related task (Bandura, 1997). Such self-perception impacts how learners approach and execute the task as well as how they adjust and shape the environments along with the completion of the task. The outcomes of the academic task would in turn impact learners' self-efficacy and perhaps future behaviors.

Bandura (1986) further suggested that self-efficacy is the fundamental belief that enables individuals to exercise various self-regulated processes As Bandura (2001) put it, "unless people believe they can produce desired results and forestall detrimental ones by their actions, they have little incentive to act or to persevere in the face of difficulties" (p. 10). In other words, if learners judge themselves to be more capable of performing a given task, they are more likely to set higher goals, make careful plans, be more metacognitively engaged, try harder, and persist longer.

Self-efficacy beliefs impact self-regulatory thinking and actions in various ways (Bandura, 1997). Take academic self-efficacy and self-regulated learning as an example. Academic self-efficacy influences the academic tasks students choose and the 
types of goals they set for themselves before starting the tasks (Pajares, 2008). Students with higher self-efficacy are more likely to engage in a challenging task and set a higher standard goal compared with their low-efficacy peers (Schunk \& Zimmerman, 2006).

Academic self-efficacy beliefs also affect how much effort students invest in working toward the goals they are pursuing, how persistent they are in the face of difficult tasks, and how much resilience they show after encountering initial failures (Schraw et al., 2006). Students with high academic self-efficacy may participate in difficult tasks more eagerly, whereas those who feel less efficacious may avoid such tasks. High-efficacy students are more likely to engage in and commit to a task and to persist to a further extent when facing initial failures than students with lower self-efficacy (Pajares, 1996).

Furthermore, academic self-efficacy beliefs influence how active students are in monitoring and evaluating the approaches they use to complete tasks and how they attribute performance outcomes. Efficacious students tend to be more acute about the strategies and processes they use to execute tasks and to reflect upon the effectiveness of such strategies and processes more often than their less efficacious peers (Pintrich \& Zusho, 2007). Students who believe in their capabilities to accomplish academic goals (i.e., those with high level of self-efficacy) attribute performance to their own efforts and 
strategies, which encourage their continuous endeavors and use of effective strategies in future tasks (Bandura, 1986; Kitsantas, 2002).

Academic self-efficacy beliefs that students hold help determine how they think and what they do with the knowledge they have and thus affect their academic performances. Researchers (Kitsantas, 2002; Schraw et al., 2006; Schunk \& Zimmerman, 2006) have shown that learners' self-efficacy perceptions and their use of self-regulatory processes are critical in analyzing their academic achievement. Research has consistently suggested that academic self-efficacy beliefs are highly correlated with learning outcomes in a broad range of settings (Bliss \& Sandiford, 2004; Schraw et al., 2006; Schunk \& Zimmerman, 2006).

Like self-efficacy, beliefs of task values and outcome attributions also play important roles in self-regulation practices (Pintrich \& Zusho, 2007). As for task values, before learners start new tasks, they have particular perceptions of the tasks, such as whether the tasks are relevant or important to them, how useful the tasks are for them, and how interested they are in the tasks. If students believe that the tasks are highly valuable, they are more likely to be metacognitively and behaviorally engaged in the tasks (Wigfield, 1994). As students proceed and receive feedback from others about the tasks, they may attempt to modify their value beliefs, which could change their use of self-regulated processes correspondingly (Pintrich \& Zusho, 2007). 
It follows that the way students attribute the outcomes after completing the tasks may lead to different feelings and the possibility of engagement in future tasks (e.g., Weiner, 1995). For example, learners may not perform well enough on the tasks to meet their desired goals. If they attribute such outcomes to poor metacognitive control or behaviors, it would have less effect on their self-efficacy and they would be more actively engaged in regulation of cognition and behaviors in the future (Schunk \& Zimmerman, 2006). Conversely, if students attribute such outcomes to lack of ability, they may raise doubts about their own self-efficacy and become less motivated in future tasks.

A number of studies have investigated the role motivational beliefs plays in self-regulation and/or self-regulated learning. For example, Chong (2007) examined how academic self-efficacy beliefs are related to the engagement of self-regulatory learning for 1,304 Singaporean seventh graders across subject areas. A significant positive correlation was noted between students' perceived academic efficacy and their tendency to be involved in self-regulatory practices. In addition, the result of hierarchical regression showed that academic efficacy made unique contributions in predicting students' engagement in self-regulatory processes while their prior achievement did not. The findings suggest that students who are more efficacious in 
their academic work may initiate more effortful and purposeful self-regulatory engagement.

Focusing on secondary school students, Jain and Dowson (2009) looked into the mathematics area only. They examined the relationship between regulation of cognition and academic self-efficacy and their possible effects on math anxiety of 232 Indian eighth grade students. Self-efficacy was found to be significantly and positively related to self-regulation, but negatively related to math anxiety. In addition, the strategies students used to regulate cognition were not directly related to math anxiety, which suggests that academic self-efficacy acts as mediator between self-regulatory strategy usage and math anxiety.

Some researchers like Niemczyk and Savenye (2001) not only examined academic self-efficacy and self-regulation, but took academic achievement into consideration as well. They explored the relationship among students' self-efficacy beliefs, self-regulatory behaviors and their academic performance as indicated by course grades in a computer literacy class of 291 students from a large southwest university. The multiple regression analysis showed that participants' self-efficacy beliefs for learning were positively related to the level of accomplishment they achieved, as were self-regulatory behaviors such as time management and elaboration (i.e., integrating and connecting new information with prior knowledge). Self-efficacy beliefs also may have 
negatively influenced the amount of stress and anxiety individuals experienced as they engaged in a task.

Similarly, Jakuboswki, Terrance, and Dembo (2002) studied the relationship among academic achievement as measured by course grades, self-regulated learning strategies and processes, and several social cognitive characteristics including self-efficacy in a learning and study strategy course with 210 students at a private university. Both self-regulated learning strategies and academic efficacy beliefs were found to be significantly correlated to academic achievement. Furthermore, the results of path analyses showed that the inclusion of self-regulatory strategies had an effect on the relationship between self-efficacy and the course grade, causing self-efficacy to have a weaker relationship with the course grade. This lowering of the strength of the relationship between self-efficacy and the course grade suggests that the effect of self-efficacy on academic achievement may be mediated by academic self-regulation.

Self-efficacy is not only highly related to self-regulated learning processes and outcomes, but more importantly, a number of studies suggest that it predicts academic performance independently of several exemplary predictors of performance such as cognitive ability and prior academic achievement (Bandura, 1997; Zimmerman, 2000b). In other words, students with similar cognitive abilities or previous academic 
achievements may differ significantly on academic performances due to the judgments and beliefs the students have about their capabilities to perform a task.

For example, in order to examine the role of self-efficacy beliefs in affecting academic achievement beyond cognitive abilities, Collins (1982) identified children of low, middle, and high mathematics ability who had, within each ability level, either high or low mathematics self-efficacy. All children were given a test on a set of mathematics problems. After the same mathematics instruction, students were given new problems to solve and an opportunity to rework those they missed. The final results showed that students' ability level was correlated to performance. However, more importantly, regardless of ability level, children with high self-efficacy completed more problems correctly and reworked more of the ones they missed. This study supported the notion that academic efficacy beliefs make a powerful and independent contribution to the prediction of performance from mental abilities. Students with similar cognitive skills may differ in achievement as mediated by their academic self-efficacy beliefs.

Similarly, Kitsantas, Winsler, and Huie (2008) examined the role of students' prior ability levels and self-efficacy in predicting academic achievement at different times in students' college lives. Participants' prior ability and self-efficacy levels were measured in the first semester in college and their grade point averages were collected at the end of the first and the second year, respectively. A correlation analysis showed that at the end 
of the first year, students' performance as measured by cumulative college GPA had a strong correlation with academic self-efficacy; a correlation which remained strong by the end of the second year. In addition, the results of hierarchical regression indicated that prior ability levels and motivational constructs including self-efficacy were both unique contributors in predicting students' academic performance at both the end of the first year and the end of the second year.

Pajares and Graham (1999) investigated the influence of various motivational variables on mathematics performance and explored whether these variables changed during the first year of middle school for 273 students. After controlling other motivation and previous achievement variables, only students' math self-efficacy made an independent contribution to the prediction of mathematics performance among all the variables both at beginning and end of the year. Findings from that study support Bandura's (1997) claim that self-efficacy belief is a unique predictor of academic outcome.

Zimmerman and Bandura (1994) investigated the relationships among self-efficacy, goal setting, and writing achievements in a college writing course. A significant positive correlation was found between self-efficacy for writing and students' goals for course achievement. Similar to their previous finding (Zimmerman, Bandura, \& Martinez-Pons, 1992), the results showed that the more students believe they are capable 
of writing (i.e., the higher self-efficacy for writing), the more challenging the goals they set for writing tasks. In addition, self-efficacy for writing was positively correlated with students' satisfaction with potential outcomes and students' actual course achievement. Furthermore, when self-efficacy and personal goals were included with the verbal subscale of the SAT score, the regression model accounted for $35 \%$ of the variance of college students' final grades in the writing course. The results supported the idea that self-efficacy belief is a significant predictor of achievement independent and above conventional exemplary predictors, including prior achievement and general cognitive ability (Zimmerman, 2000b).

In sum, how students control their motivational beliefs is a unique part in self-regulation theory (and self-regulated learning), which partially distinguishes it from metacognition theory. The motivational dimension in self-regulation theory (and self-regulated learning) provides some legitimate explanations as to why some students actively regulate their thinking and behaviors during the learning process whereas some others fail to do so.

\section{Regulation of Behavior}

So far, I have mainly focused on how individuals (and learners in particular) regulate their thinking (i.e., regulation of cognition) and motivation (i.e., regulation of 
motivation) in the learning process. The third aspect of self-regulation is regulation of behavior, involving individuals' regulation and control of their overt behaviors.

One of the behavioral regulatory processes often mentioned is self-observation. Self-observation requires students to pay attention to their own behaviors usually by taking notes and keeping records or diaries (Camahalan, 2006; Zimmerman \& Kitsantas, 1997). Self-observation is an ongoing behavior which allows students to know whether and to what degree they are approaching a goal, and if not, what needs to be done.

Time and effort management is another typical self-regulatory behavior. It refers to how students allot and prioritize their time and effort for various activities based on their own needs and expectations (Ogonor \& Nwadiani, 2006). Time and effort management is particularly important in university settings compared with those in primary education. In elementary and secondary schools, students are guided by teachers, parents, and authoritative others about how to use their time. Specific time is assigned for classes, homework, extracurricular activities, etc. By contrast, students at the college level are considered to be responsible adults who are able to make appropriate decisions on time utilization (Ogonor \& Nwadiani, 2006). College and university students thus have to determine how to manage and utilize time for various activities by themselves, based on their own needs and expectations. 
Considering that both having a paid job and participating in social events are regular components in college life, time and effort management suggests that students need to balance time and effort they spend on study, work, and social activities. Time and effort management is also related to whether or not students spend adequate time on academic-related activities, such as reading the text, completing assignments, and preparing reports and exams outside of class. In addition, as they proceed in the tasks, students may realize the insufficiency (or overspending) of their effort and time and therefore adjust their time and effort devoted to the tasks based on their goals.

A number of studies have supported the claim that effort and time management positively influence academic performance (Bliss \& Sandiford, 2004; George, Dixon, Stansal, Gelb, \& Pheri, 2008; Lahmers \& Zulauf, 2001; Young, Klemz, \& Murphy, 2003). Good time management for academic activities generally is positively related to students' performance and attitude with high achieving students being better at time planning and managing their time than average achieving students (Eilam \& Aharon, 2003; Ogonor \& Nwadiani, 2006). By contrast, poor time management has been found to predict to underachievement, academic failure and withdrawal (Balduf, 2009; Goldfinch \& Hughes, 2007).

Time management is considered by many as one dimensional; however, several researchers have defined multiple dimensions of time management. Bliss and Mueller 
(1987) first differentiated time management for short-range, routine tasks and time management for long-term tasks in the Study Behavior Inventory, an instrument that measures the study behaviors of students enrolled in colleges and universities. Time management for short-range tasks refers to students' ability to plan and prepare daily and routine academic activities, such as readings, assignments for class sessions, and review of lecture notes. Students who score high on this dimension tend to organize their schedule well in the short run with specific techniques; for example, writing a to-do list and prioritizing the daily schedule. Time management for long-term tasks deals with students' ability to schedule and carry out specific long range and non-recurring academic tasks that are not imminent, such as writing term papers and studying for examinations. Students who score high on this dimension are likely to set goals for the entire tasks and divide those into multiple steps, set and keep track of timetables for different stages or steps during the process, review materials and work on major projects or assignments periodically without deadlines being imminent. These two dimensions of time management was supported by studies carried out by Britton and Tesser (1991) and Garcia-Ros et al. (2004), both of which carried out factor analysis in the study of time management.

In addition, behavioral self-regulation is accompanied by the attribution students made about their learning outcomes. For example, as indicated previously, if the 
academic outcomes fall short of the desired goals and students attribute it to their own poor behaviors, they are likely to devote more time and effort, be more persistent, and seek help from peers or teachers (Zimmerman \& Kitsantas, 1999). On the other hand, if students attribute the same outcomes to lack of ability, they may decrease their effort, spend less time, or even avoid similar tasks altogether in the future.

A number of studies have examined the relationship between self-regulatory behaviors and students' learning outcomes. For example, in Zimmerman and Kitsantas's (1997) study mentioned earlier, they also examined the impact of self-observation on the acquisition of dart-throwing skill among 90 girls. The girls were randomly assigned into the experimental group who were asked to record their own progress or the control group who did not self-record. The result showed that self-observation had a significant effect on participants' reaction to potential outcomes and their dart throwing performance. The girls who took notes and self-recorded their learning efforts not only reported greater satisfaction with their performance than those who did not self-record, but also surpassed the dart-throwing proficiency of non-self-recording group as well. The study suggested that self-observation helps learners be aware of their own progresses and the places where they could improve to achieve better outcomes. 
As for time management behaviors, Nonis and Hudson (2006) investigated the effect of time spent studying on academic performance for 264 college business students. The results of moderated multiple regression showed that study time and students' cognitive ability together accounted for $25 \%$ of the variance in predicting academic performance. Furthermore, an interaction effect was found between study time and students' cognitive ability. Specifically, among those who spent a lot of time studying, students with high cognitive ability levels showed significantly better academic performance than those with low ability. Meanwhile, among those who spent little time studying, the difference in academic performance between students with high and low ability was much less salient. The study suggested that devoting an adequate amount of time studying may be necessary yet insufficient for satisfactory academic achievement. Unfortunately, the researchers did not measure how students spent their time studying, which could have provided more insight about its impact on academic outcomes.

Witkow (2009) instead looked at both the differences in the amount of time students spent and their patterns of time management in the academic and social domains as related to how successful they were at school. Over 700 ninth grade students completed daily diaries every night for 14 consecutive nights to provide information on their time use for the day. The results of hierarchical linear regression showed that over the 14-day study period, high achieving students spent more time studying without spending 
less time with their friends than lower achieving students. Furthermore, high achieving students and low achieving students differed in terms of how they managed and used time between weekdays and weekends and on a daily basis. The results imply that both the amount of time spent on studying and the way of managing time are related to academic achievement.

Similarly, George et al. (2008) utilized time diaries and questionnaires to assess the influence of several personal and cognitive factors on academic success of 231 Canadian college students. The results of stepwise multiple regression showed that both more time spent studying and better time-management skills were significant predictors of higher GPAs. The results support previous findings that time-management practices are central to academic success (Britton \& Tesser, 1991). Britton and Tesser found that time-management skills were not only positively associated with GPAs, but better predictors of GPAs than was cognitive ability as measured by SAT scores.

Kitsantas et al. (2008) investigated the role of time management in students' academic achievement at various times in their college years. It turned out at the end of both the first and the second year, academic performance showed strong correlation with time management. Furthermore, hierarchical regression analysis suggested that time management is a significant and unique contributor in predicting students' academic performance at the end of both the first year and the sophomore year. 
Meanwhile, some researchers have examined multiple dimensions of time management. For example, Bliss and his colleagues (Bliss \& Mueller, 1987, 1993; Bliss \& Sandiford, 2004) have consistently found positive correlations between students' academic performance with both time management for short-range, routine tasks and time management for long-term, non-recurring tasks.

Britton and Tesser (1991) also examined the effects of time management on academic achievement over a long period, separately from academic ability measured by SAT scores with 90 college students. Regression analyses showed that two time-management components - time attitudes (i.e., the sense of control over one's use of time) and short-range planning - were significant predictors of college cumulative GPA and accounted for more variance than did SAT scores. The results suggest that time management practices have critical influences on college achievement. However, contrary to the two researchers' expectations, long-range planning was not found significantly related to achievement. This could be explained by the fact that the participants were in their freshmen year when reporting their time management practices and the new college environment tends to involve rapid and frequent change. Perhaps in such a type of environment, a short-term planning schedule is more efficacious than long-term planning. In other words, long-range planning may be more important in a less volatile academic environment. 
Garcia-Ros et al. (2004) factor analyzed time management practice as well, based on the responses from 350 Spanish high school students. Three factors emerged -short-range planning, long-range planning, and time attitudes, which were supported by confirmatory factor analysis as well. They further examined the predictive capability of time management practice for academic achievement. Unlike Britton and Tesser's study, the results of their study showed that long-range planning was the strongest predictor of the students' achievement. The authors attribute the discrepancy to the different academic levels of students and societal contexts of the studies.

Balduf (2009) on the other hand aimed to understand the stories of students who are academically unsuccessful. She interviewed 7 first-year college students who either were on academic probation or who had earned an academic warning in order to examine to what those students attributed their underachievement. The results of narrative analysis showed that a problem with time management is a major factor that students felt contributed to their underachievement. Participants mostly studied shortly before exams, did not know how to pace their studies, waited until the last minute to study to prepare for course assessments, and were easily distracted or unable to balance academics and social activities. The results suggested that a failure to manage time well easily becomes a barrier to students' adjustment to university level academic requirements and to college life in general. 
Additionally, several other studies have focused on a particular kind of poor self-regulatory behavior -- procrastination, and its relationship with academic performance. Procrastination refers to the tendency to delay beginning or completing intended tasks (Steel, 2007). Procrastination often occurs when students attempt to avoid the tasks or decrease their efforts in the tasks. Procrastination behavior is considered a "self-regulation failure of performance" (Ferrari, 2001, p. 391). Unlike students who are knowledgeable and proactive in managing time and effort they spend on learning, procrastinators fail to regulate their learning behaviors effectively (Ferrari, 2001). Procrastination tends to lead to negative outcomes (e.g., incomplete assignments, cramming, and giving up studying when more attractive alternatives are available), overall poor performance on tests and activities, and less satisfaction with study performance (Dewitte \& Schouwenburg, 2002; Ferrari, 2001; Fritzsche, Young, \& Hickson, 2003; Wolters, 2003).

Schouwenburg and Groenewoud (2001) examined students' actual study behaviors based on their self-reported academic procrastination tendency. A general pattern that was found for participants overall was that the number of hours students typically study per week accelerates at an increasing rate as the final examination becomes imminent. More importantly, for those students who identify themselves as procrastinators, such a pattern is more dramatic. Specifically, procrastinators showed a significantly higher 
rate of acceleration than those who reported they did not or were less likely to procrastinate. This suggested that in general procrastinators are very likely to start doing assignments and studying only as the deadline approaches.

Tuckman (2002) compared students' self-regulated learning and academic performance based on self-reported levels of procrastination (i.e., high, moderate, low levels of procrastination) of 216 students in a web-based course. The results showed that independent of academic capability, all three procrastinator groups showed significant differences in the processes and strategies students used to regulate their learning. In addition, both low and moderate procrastinator groups had significantly higher course grades than did high procrastinators. The results suggested that a high level of procrastinating was a serious liability in typical college courses which demand high cognitive loads as well as imposed time limitations.

From the social cognitive perspective, regulation of behavior is an equally important aspect as regulation of cognition and regulation of motivation in self-regulation theory (and self-regulated learning). Individuals' behaviors are considered as the product of the interaction between personal factors (i.e., their thinking/cognition and motivation) and environmental factors (Bandura, 1997). Regulation of behaviors not only manifests in how individuals regulate their thinking and motivation, but also demonstrates how environment influences such regulatory processes. 


\section{The Interrelationship of Person-Behavior-Environment}

The social cognitive perspective of self-regulation (and self-regulated learning) considers self-regulatory processes to occur during individuals' interplay with the environment and it explicitly emphasizes the influences of environmental/contextual factors in learners' self-regulation. As environmental factors change, individuals will adjust their reactions and self-regulatory processes correspondingly, which in turn affects the characteristics of future learning environments.

Environmental factors include classroom climate and dynamics, the feedback from teachers and peers, availability and favorability of physical environments, etc. For example, students need to be aware of classroom rules, grading policies, and teachers' expectations for them and other contextual norms before directing their learning approaches and strategies. External feedback is also critical in shaping and/or changing the way students think, feel and act in the learning process. Actively seeking help and feedback from instructors and peers provides students with knowledge and information that could facilitate their learning. In addition, as much of the learning takes place outside the classroom at the college level, how students control and construct the learning environment also impacts their learning (Pintrich \& Zusho, 2007). Specifically, for students who are easily distracted, constructing a study environment with less distraction allows them to concentrate and thus is conducive for learning. Clearly, as 
person-behavior-environment interaction continues, the study environment constantly provides cues, which students have to take into consideration as they employ or adjust self-regulatory processes.

As much as I have described different aspects of self-regulated theory (and self-regulated learning) separately, the intention was not to isolate each of them. Rather, the fundamental idea of self-regulation theory (and self-regulated learning) is that in any complex human functioning (including learning), various factors interact with each other and consequently influence the outcomes. In the case of academic learning, how students regulate thinking and motivation, how they react to the environment, and how they behave will all influence each other and also be influenced by each other. Specifically, students bring certain thinking patterns and motivational beliefs into the learning environment and behave accordingly. The way students interpret the learning outcomes determines how favorably they judge the environment. The environment may reinforce or change students' motivations and feelings, which would in turn modify their thinking and perhaps future learning behaviors (Pajares, 2008). Therefore, from the social cognitive perspective, self-regulated learning is a reciprocal and ongoing process, with each component influencing and being influenced by the others (Bandura, 1997; Schunk \& Zimmerman, 2006; Zimmerman, 2000a). 


\section{Summary}

In order to succeed academically in college and university, students need to exercise appropriate studying behaviors and habits. It is critical that students be able to direct and control their actions in the learning process. From the social cognitive perspective, self-regulated learning allows students to take into account personal, behavioral, and contextual factors. As students regulate their own thinking, motivation, and behaviors in response to contextual factors, they initiate and sustain an active learning process and that consequently leads to academic achievement.

\section{Q Methodology and Q Factor Analysis}

This study employed Q factor analysis to study college students' self-reported study behaviors. Q factor analysis is a method that enables researchers to categorize people based on their patterns of responses and opinions on a certain topic (Brown, 1991). It is called $\mathrm{Q}$ in order to contrast it with $\mathrm{R}$ analysis, which refers to a generalization of Pearson's $r$, mostly used in the behavioral study of relationships among distinct traits, such as academic ability (Addams \& Proops, 2000).

It should be first noted that $\mathrm{Q}$ factor analysis is often mentioned along with another

method, namely Q methodology. Q factor analysis and Q methodology share the same paradigm and statistical analysis technique (Newman \& Ramlo, 2010). However Q factor analysis is a distinctive method from Q methodology. What differentiates Q 
factor analysis and Q methodology is the way data are collected. Q methodology requires the participants to rank-order a set of statements on the topic of interest according to their perceptions and beliefs. This process is known as Q-sorting (Stephenson, 1975). Q factor analysis need not involve Q-sorting. Instead, in Q factor analysis, data can be collected through various sources such as interviews and surveys (Newman \& Ramlo, 2010).

Q factor analysis attempts to reveal a person's responses or opinions on a given topic and the extent to which that person's responses are shared by other individuals (McKeown \& Thomas, 1988). These individuals could therefore be considered as a typical group with a similar pattern of behaviors or responses on the issue, also known as a typology of subjects (McKeown \& Thomas, 1988; Newman \& Ramlo, 2010). Equipped with Q analysis, researchers are able to further compare various typologies of individuals in order to find out the similarity and difference among behavior patterns held by these groups of people.

In traditional research using $\mathrm{R}$ analysis, researchers seek to determine the relationship among variables represented by instrument items (McKeown \& Thomas, 1988). In other words, it generates patterns across particular variables. By contrast, Q factor analysis establishes patterns within and across individuals; that is, the patterns are generated from people's similar responses on a given issue (Galayda, 2006). Therefore, 
in a Q study, it is the data of individuals that are examined in order to identify different types of participants who responded to the topic in a similar way. Simply put, Q factor analysis groups people rather than items (Newman \& Ramlo, 2010).

This brings up a related characteristic of $\mathrm{Q}$ factor analysis. This is, that because persons are considered the variables, a large sample size and random sampling are not required in Q factor analysis (Brown, 1986; Smith, 2001). As McKeown and Thomas (1988) stated, Q analysis typically involves small numbers of participants, and this is psychometrically acceptable because in essence it is an inductive and exploratory process rather than a deductive or predictive one. In sum, $\mathrm{Q}$ factor analysis is a sophisticated and appropriate methodological approach to investigate students' patterns of study behaviors. 


\section{CHAPTER III}

\section{METHODS}

The current study examined study behaviors and habits of university undergraduate students by determining: (a) how students can be grouped based on their self-reported study behaviors, and (b) whether the group membership is related to students' academic achievement. The research design used in this study was an ex post facto design using Q factor analysis as the statistical tool.

\section{Research Design and Rationale}

Student participants responded to a survey instrument, the Study Behavior Inventory, by indicating how often they believe certain statements referring to study behaviors applied to them. Responses were Q factor analyzed in order to generate typologies of students representing different patterns of study behaviors. The typologies were then examined with students' academic performance for possible correlations.

In this study, Q factor analysis was used to analyze data instead of the traditional $\mathrm{R}$ factor analysis. Q factor analysis and $\mathrm{R}$ factor analysis have different fundamental goals. Traditional $\mathrm{R}$ factor analysis is generally used to investigate the interrelationship among variables (i.e., instrument items). By contrast, $\mathrm{Q}$ analysis allows the researcher to group people based on their opinions, behaviors, or responses on a given topic (Brown \& Pirtle, 2008). Since I was interested in whether students could be categorized 
according to their self-reported study behaviors, Q factor analysis was the appropriate choice for this study.

Using Q factor analysis made this study essentially different from those using $\mathrm{R}$ factor analysis because the study was not exploring the patterns/factors underlying instrument variables, which the $\mathrm{R}$ methodology intends to do. This $\mathrm{Q}$ study instead examined the participants in relation to each other and resulted in a pattern of intercorrelations among participants (McKeown, Hinks, Stowell-Smith, Mercer, \& Forster, 1999) based on their self-reported study behaviors. In other words, Q factor analysis groups people instead of items (McKeown \& Thomas, 1988).

By using $\mathrm{Q}$ factor analysis, my interest was to examine study behaviors among college students and to determine how these different patterns of study behaviors were related to their academic achievement. I took the position that students vary in patterns of study behaviors. That is, students may systematically differ in what they actually do when they are studying (e.g., how they set and accomplish their study goals, how they approach lectures and tests, and how they take advantage of time for study).

Some researchers may be more familiar with Q methodology than Q factor analysis. It should be noted that $\mathrm{Q}$ factor analysis is different from $\mathrm{Q}$ methodology, although they both fit the mixed-methods strategy and share some characteristics and procedures (Newman \& Ramlo, 2010). What differentiates Q factor analysis and Q methodology is 
the way data are collected. Q methodology requires the participants to follow a rank-ordering procedure by ordering a set of statements on the topic of interest according to their perceptions and beliefs. This process is known as Q-sorting (Stephenson, 1975). Q factor analysis does not necessarily involve Q-sorting. Instead, when using Q factor analysis, data can be collected through various sources such as interview and survey (Newman \& Ramlo, 2010). In this study, data were collected using a survey instrument. Q factor analysis and Q methodology do share a similar approach to data analysis, which will be explained in that section.

\section{Participants}

The main interest of a $\mathrm{Q}$ factor analysis is to find out the characteristics of various responses and behaviors among the participants and the extent to which they are similar or different (Brown, 1993; Galayda, 2006). To do so, in Q factor analysis, participants are considered the variables and the instrument items are considered the subjects in the sample. In other words, Q groups persons instead of items based on their responses to a topic (Newman \& Ramlo, 2010). As a consequence, Q does not require a large sample of participants. A sample with $30-50$ subjects is usually considered more than adequate mathematically (Brown, 1986; Wilson, 2002). Having said that, Newman and Ramlo (2010) posit that if any part of a study will be using statistical analysis such as linear regression, a large sample would be very desirable in order to have satisfactory statistical 
power. This was the case for the current study because the second objective of the study was to examine the relationship between group membership based on study behaviors and students' academic achievement. In order to test such relationship, I utilized multiple regression, which is subsumed under the general linear model.

This study used a convenience sample composed of 152 undergraduate students in total. The participants were all enrolled in fall semester of 2010 at Florida International University (FIU). Florida International University is a multiple-campus, publicly funded university located in the Miami metropolitan area. The university has a diverse student body that is 59\% Hispanic, 17\% Caucasian, 13\% African American, 4\% Asian or Pacific Islander, and 7\% other racial/ethnic groups. Approximately $77 \%$ of students at FIU are undergraduates (Florida International University: About FIU, n.d.). The study included both female and male participants from diverse racial/ethnic groups with a dominant portion in their late teens and early 20 s.

All participants were undergraduates at Florida International University's Modesto Maidique Campus. The participants were recruited with the cooperation of course instructors. I approached faculty members from different departments at Florida International University and solicited their permission to administer the instrument to their students during a regular class session. 


\section{Instrumentation}

The current study investigated college and university students' study behaviors and habits. For this study, the Study Behavior Inventory (SBI) developed by Bliss and Muller (1993) was used as the measurement tool. The SBI is a 46-item self-report instrument that measures study behaviors and habits from students enrolled in colleges and universities. Participants respond to a series of statements on a 4-point scale according to how often a specific statement applies to them. The choices are (1) rarely or never, (2) sometimes, (3) often or usually, or (4) always or almost always.

The SBI was designed to reflect students' typical study behaviors. Factor analysis of the instrument yielded three factors underlying the construct of study behaviors: (a) feelings of academic self-efficacy, (b) management of time for routine, recurring tasks, and (c) management of time for long-term, specific, nonrecurring tasks (Bliss, Kerstiens, \& Marvin, 2000). The instrument has established good estimates of validity and reliability (Bliss \&Mueller, 1993). It evidenced high internal consistency in all factors, with Cronbach's alpha reliability estimate for the scores on the three factors of the instrument ranging from .70 to .86 and a factor structure consistent with the literature on study behaviors and self-regulation (Bliss \& Mueller, 1993). Another indication of construct validity is the high correlation found between SBI scores and GPAs (Bliss \& Mueller, 1993). 
Self-reported current grade point averages were used to indicate students' academic performance. Data about participants' sex, age, the degree programs they were pursuing, and their present enrollment status were collected.

\section{Data Collection \& Procedures}

During the fall semester of 2010 , I visited all participating classes to administer the Study Behavior Inventory during regular class times. I introduced myself and invited students to complete the SBI survey. An information form was read. I told all participants that they were free to terminate participation at any point and all data collected would be kept confidential and secure. Each student who agreed to participate filled out the SBI survey. I notified participants that there are no right or wrong answers and their responses should be completely based on what they believe they actually do. In addition, participants were asked to answer five extra questions listed at the bottom of the survey. They reported their current grade point averages to indicate academic achievements. Information concerning students' sex, age, major degree program, and enrollment status (i.e., full-time or part-time) was also collected. In order to maintain participant anonymity, no further information was collected.

\section{Data Analysis}

Data analysis involved a sequence of statistical procedures: correlation, $\mathrm{Q}$ factor analysis, and computation of $\mathrm{Q}$ factor scores (Newman \& Ramlo, 2010). The data 
collected by the SBI were correlated and factor analyzed in order to find significant factors among the students. The PQMethod program (Schmolck, 2011) was utilized to perform the statistical analyses.

As noted earlier, in a $\mathrm{Q}$ factor analysis, participants are considered variables. Thus, in Q factor analysis the completed individual survey responses are first correlated with one another in order to calculate the degree to which these responses are similar or different. A good way to understand Q analysis is to envision it as inverted R matrix. That is, the $\mathrm{R}$ data matrix will be rotated 90 degrees to have a $\mathrm{Q}$ data matrix with columns being persons and rows being statement items. Therefore, given $\mathrm{N}$ persons in a Q data set, an $\mathrm{N} x \mathrm{~N}$ correlation matrix with all possible pair-wise correlation coefficients between participants will be calculated. A correlation coefficient $(r)$ measures each statement item's relationship with each of the other items. A high positive correlation means the two participants rated the items in a similar way and thus shared a similar pattern on the issue. For the current study, since there were 152 participants, the correlation matrix consisted of $23,104(152 \times 152)$ correlation coefficients.

Determining correlations between the SBI items was not the principal purpose of the data analysis, but it served to prepare the data for factor analysis. Q factor analysis (Cattell, 1978) is the fundamental statistical technique used to show how participants are being grouped (McKeown \& Thomas, 1988). Q factor analysis enables the researcher 
to reduce a large amount of data to a small number of factors without losing much information (Newman \& Ramlo, 2010).

Before running a factor analysis, researchers have to choose the method of extraction and rotation. Many Q methodologists prefer centroid extraction with hand rotation over the frequently used principal components extraction with varimax rotation. Although this technique has been widely dismissed among users of $\mathrm{R}$ factor analysis, these Q methodologists believe that the former combination (i.e., centroid extraction with hand rotation), because of its indeterminacy, allows researchers to examine data from a theoretical rather than a statistical standpoint (Brown, 1980; Stephenson, 1975). Nevertheless, principal components extraction with varimax rotation is also widely employed in Q-studies (McKeown \& Thomas, 1988).

For the current study, the data were factor analyzed with principal components extraction. Several Q methodologists (e.g., Brown, 1971; McKeown \& Thomas, 1988) have suggested that there is little statistical difference between using principal components, centroid, or any other available method. Regardless of the statistical procedures employed, the results of the factor structures would have little difference (Burt, 1972). In addition, varimax rotation was used in order to "maximize the purity of saturation [as estimated by loadings] of as many ... [items] as possible on one or the other of the ... factors extracted initially" (McKeown \& Thomas, 1988, p. 52). The 
purpose of choosing principal components extraction with varimax rotation was to keep the subjectivity of the researcher at a relatively low level.

When correlation matrices are analyzed by the PQMethod program they will generate a factor matrix table. The factor matrix provides four important pieces of information: (a) the original and rotated factors of responses, (b) factor loading for each respondent on each factor, (c) the defining respondents for each factor, and (d) an array of z-scores of each instrument item for each factor type. The emerging factors are called Q factors, also known as typologies. A Q factor characterizes a group of individuals responding to statement items in a similar way and having a similar behavioral pattern (Smith, 2001). For example, if all respondents have similar responses on the topic of interest and correspondingly score statement items in the same way, all correlations will be high and positive and only one Q factor would emerge.

Likewise, if participants respond to the items in two distinct ways, they will be clustered into two separate Q factors, and so on.

As in any other factor analysis, the immediate question to ask is whether or not a factor is interpretable. A traditional rule used to make such decision is the eigenvalue criterion, whereby a factor's significance is estimated by the sum of the squared factor loading of all variables for the factor. By convention, the cutoff eigenvalue is set at 1.00 , and only those factors with eigenvalues greater than or equal to 1.00 are considered 
interpretable. However, using the eigenvalue criterion alone in $\mathrm{Q}$ factor analysis could lead to two potential problems (McKeown \& Thomas, 1988). First, such a criterion can be misleading in the sense that the eigenvalue of a factor could be greater than 1.00 purely due to the person sample (i.e., the participants) size and/or statement sample (i.e., the instrument) size (Brown, 1980; McKeown \& Thomas, 1988). More importantly, such a cutoff rule could leave out important information from the data. That is, a factor may be considered not interpretable in the statistical sense (and thus be discarded by convention), but can provide unique practical insights on the issue from the theoretical standpoint (Brown, 1980; McKeown \& Thomas, 1988).

Therefore, in addition to using the eigenvalue criterion, the significance of each $\mathrm{Q}$ factor should also be decided by whether or not it would make a unique contribution to understanding the perspectives of the participants. The practical rule, suggested by Stephenson (1967, p. 24) and widely used since, is that any factor with two or more subjects highly loading on it will be accepted (Addams \& Proops, 2000). The original factors will then be rotated to a meaningful solution with principal components extraction and varimax rotation.

The second set of information from the factor matrix is the factor loadings. Each participant will be assigned a factor loading value on each factor found in the analysis. For example, assuming that two factors emerge from $Q$ factor analysis, each participant 
will then have a factor loading value for each of these two factors. Each participant's loading on a given factor indicates the magnitude of association between a person's response and the underlying factor. A participant's loading on a factor can be either positive or negative, and represents that person's sharing or rejection of the concepts underlying that factor (McKeown \& Thomas, 1988).

Factor loadings used to be referred to as factor saturation (see Brown, 2010a). Factor saturation could be understood as the degree to which an individual falls into a factor. For example, if a person has a very high loading on a given factor, it means that person's behavior or response is saturated with the factor. Another person with a very low loading on a factor is "less saturated and ... therefore expected to display an attitude with fewer traces of the factor" (Brown, 2010a, para. 1).

As for the third component of the factor matrix, participants who loaded strongly on a factor are the ones defining that factor. The computer program will automatically indicate the defining respondents by placing an "X" next to that respondent's factor loading value. These defining subjects are the key to understanding the factors generated from the analysis as these subjects' shared behaviors are the primary representation of the underlying patterns on the topic.

Fourth, the $\mathrm{Q}$ factor analysis will generate an array of z-scores on each instrument item for each factor type of participants. A z-score represents the average score of an 
item based on the responses from all participants of a factor type on that particular item.

Displaying the z-scores of every statement item shows different shapes of responses which representing different types of participants.

For example, Table 1 shows hypothetical z-scores of four item statements for each type of participants. According to this table, the shapes for the two types of participants are represented in Figure 2. From Figure 2, the researcher could clearly identify two distinct typologies (of people) that exist in the study.

Table 1

Example: Array of z-scores for Each Factor Type

\begin{tabular}{lccc}
\hline Statement & Type I & Type II & Difference \\
\hline 1. I complete my homework assignments on time. & 1.6 & 0.45 & 1.15 \\
$\begin{array}{l}\text { 2. When reading a long chapter, I stop periodically } \\
\text { and review the main points that have been presented. }\end{array}$ & 1.02 & 0.31 & 0.71 \\
$\begin{array}{l}\text { 3. In preparing papers, I make certain that I clearly } \\
\text { understand what is wanted before I begin to work. }\end{array}$ & 0.99 & 0.61 & 0.38 \\
$\begin{array}{l}\text { 4. I watch too much television, and this interferes } \\
\text { with my studies. }\end{array}$ & -0.70 & 0.55 & -1.25 \\
\hline
\end{tabular}

NOTE: The data presented in this table are not the actual data from my study.

In other words, the Q factors or typologies are based on people's responses to various statements from the instrument (Newman \& Ramlo, 2010). In addition, the z-score for each statement allow the researcher to compare across types and helps understand the consensus and divergence among different types of participants. 


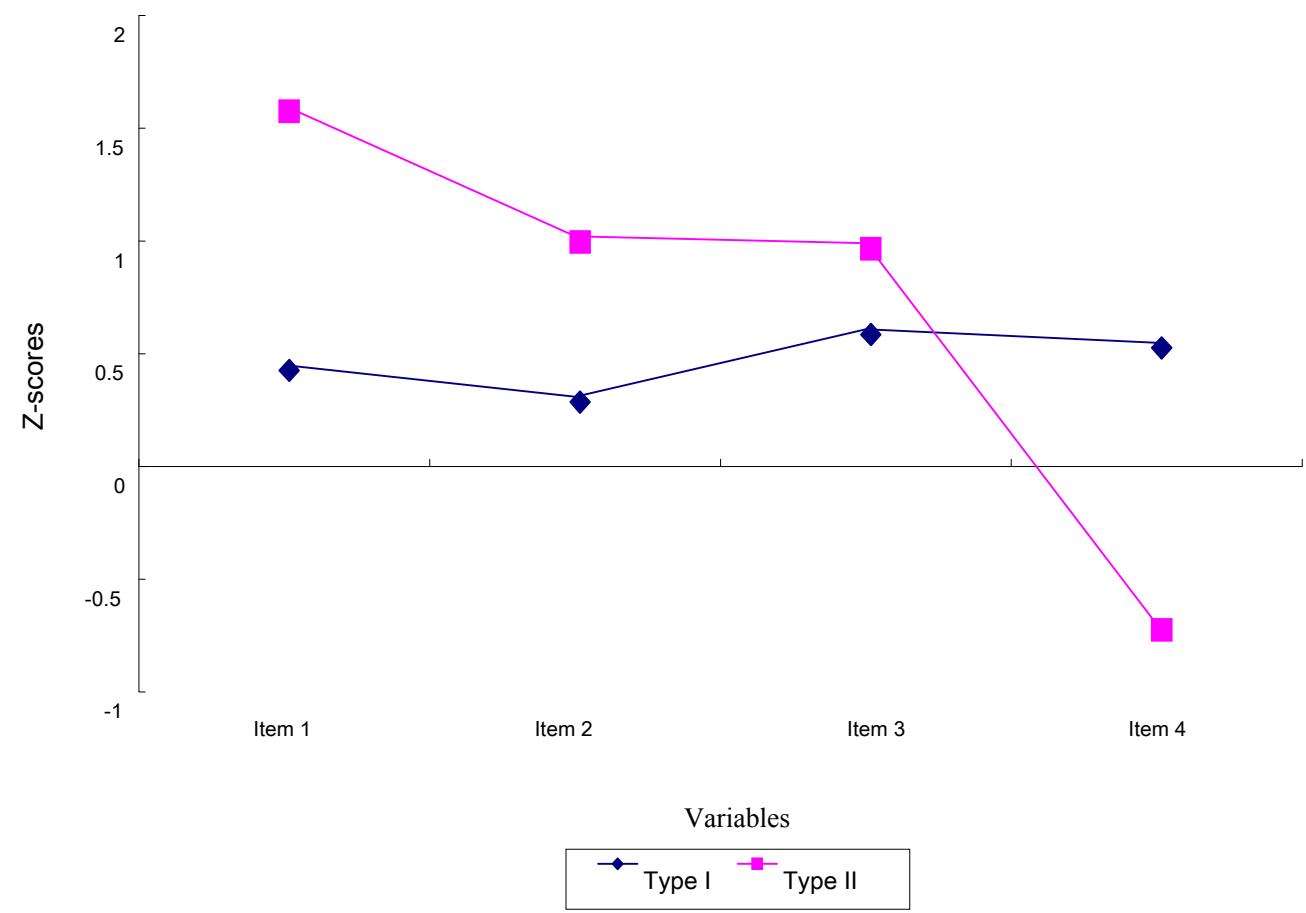

Figure 2. Example: Q factor analysis results with two typologies.

As in other types of factor analysis, factors emerging from Q factor analysis are sample specific and may be unstable. Newman and Ramlo (2010) therefore strongly recommend cross-validating the factors when doing a $\mathrm{Q}$ factor analysis. Meanwhile, other researchers (e.g., Brown, 2010b) believe that factors that emerging from a sample do not need to be generalized beyond this particular sample and the absence of factors in a different sample (or setting) would not undermine the factors that have been found in the previous sample. For researchers with this latter view, cross-validation is unnecessary. The assumption that is being made in the current study is that the findings from this sample could have implications beyond the sample itself and thus contribute to the understanding of the population. Therefore, while it is legitimate to suggest that the 
factors from some Q studies only matter within particular samples and do not require further investigation, I cross-validated in order to test whether the factors emerged from the current study are stable or not. I randomly divided the sample of participants in half to see what types of group membership emerged from one half and cross-validated the fctors from the other half sample. The factors that replicated between two half samples were judged to be more stable in the population than the others (Newman \& Ramlo, 2010) and used for the final data analysis and interpretation.

Finally, the correlations between students' grade point averages and typologies of students' study behaviors was examined to determine the relationship between students' study behaviors and their academic achievement using multiple regression techniques. Student sex, major, age, and enrollment status were controlled in multiple regression in order to determine how much of the variance of academic achievement was accounted for by typologies of student study behaviors, beyond and above their sex, major, age, and enrollment status. 


\section{Chapter IV}

\section{DATA ANALYSIS}

The current study examined typical study behavioral patterns of university

undergraduate students and their relationship with the students' academic achievement.

Specifically, this study investigated (a) how students can be grouped based on their

self-reported study behaviors using Q factor analysis, and (b) whether group membership is related to students' academic achievement by using multiple regression. This chapter presents a description of the sample, outcomes of the Q factor analysis, and the tests of hypothesis concerning the relationship between typologies of students and academic achievement.

\section{Description of the Sample}

Demographic information of the participants was collected to explore variables that theory suggests might be related to study behavior group membership. These variables were sex (Pajares, 2002; Pintrich \& Zusho, 2007), age (Dembo \& Eaton, 2000; Pintrich \& Zusho, 2007), major (Pajares, Britner, \& Valiante, 2000), and enrollment status (Holder, 2007). The researcher distributed 177 copies of the Study Behavior Inventory instrument to undergraduate student volunteers. One hundred fifty five participants returned their responses. Among the155 responses, three were incomplete and thus were not included in the $\mathrm{Q}$ factor analysis. The data analysis was based on a total of 
152 instrument responses. More than $60 \%$ of the respondents were women whereas less than $40 \%$ were men (Table 2). Participants' ages ranged from 18 to 50 years old ( $M=$ 23.93, $S D=4.89)$. Participants were from a variety of disciplines including education, STEM (science, technology, engineering, and mathematics), business, and several others (Table 3). Four-fifths of the participants were enrolled at FIU as full time students (Table 4).

Table 2

Participant Characteristics by Sex

\begin{tabular}{lccc}
\hline & \multicolumn{3}{c}{ Sex } \\
\cline { 2 - 4 } Statistic & Male & Female & Total \\
\hline Frequency & 56 & 96 & 152 \\
Percentage & $36.8 \%$ & $63.2 \%$ & $100 \%$ \\
\hline
\end{tabular}

Table 3

Participant Characteristics by Major

\begin{tabular}{lcccccc}
\hline & \multicolumn{6}{c}{ Major } \\
\cline { 2 - 7 } Statistic & Education & STEM & Business & Other & Unknown & Total \\
\hline Frequency & 72 & 47 & 22 & 10 & 1 & 152 \\
Percentage & $47.4 \%$ & $30.9 \%$ & $14.5 \%$ & $6.6 \%$ & $0.6 \%$ & $100 \%$ \\
\hline
\end{tabular}

Table 4

Participant Characteristics by Enrollment Status

\begin{tabular}{lcccc}
\hline & \multicolumn{4}{c}{ Enrollment Status } \\
\cline { 2 - 5 } Statistic & Full-time & Part-time & Unknown & Total \\
\hline Frequency & 122 & 29 & 1 & 152 \\
Percentage & $80.3 \%$ & $19.1 \%$ & $0.6 \%$ & $100 \%$ \\
\hline
\end{tabular}




\section{Q Factor Analysis}

Q factor analysis was based on a total of 152 participants' responses on the SBI instrument. The results of the Q factor analysis include (a) the Q factors, (b) the defining participants for each factor with their factor loadings, and (c) the array of factor scores of each instrument item for each factor type.

\section{Q Factors}

Q factors represent common variance in the participants' responses. Principal components extraction and varimax rotation were used to determine the number of $\mathrm{Q}$ factors. To begin with, PQMethod software forces all participants' responses into a maximum eight factors as the default. As mentioned in Chapter 3, in Q factor analysis, a factor is a people factor. Each people factor represents a type of participant based on their responses to the topic being examined; in this case, students' study behaviors. The terms factor(s) and type(s) are used interchangeably in this chapter.

In order to assess the strength of the factors, the eigenvalue criterion was used. An eigenvalue defines the strength of a factor as estimated by the sum of its squared factor loadings (McKeown \& Thomas, 1988). A factor with an eigenvalue of 1 or greater is considered for further analysis. Using the eigenvalues, the researcher can also determine the percentage of the total variance explained by a given factor. Meanwhile, as mentioned in Chapter 3, another method of determining interpretable factors is to 
examine how many participants are significantly loaded on a given type. Any type with two or more significantly loaded respondents is considered interpretable (Brown, 1980). This criterion was also used in the current study in order to examine whether the result supports the one yielded by the eigenvalue criterion.

The unrotated eight factor solutions (i.e., the default) showed that factors 6,7 , and 8 each accounted for a very small portion of the total variance and/or did not have an adequate number of respondents highly load on them. These three factors did not provide enough help in interpreting student types. Therefore, when using varimax rotation, the researcher reexamined the data beginning with the five factor solution, followed by four, three, and two factors. Among these, the two-factor structure provided the most stable and interpretable description of participant types. Table 5 shows the two factors with their respective eigenvalues and percentages of explained variance. Factors 1 and 2 combined explained $38 \%$ of the observed total variance in the data.

Table 5

Two-Factor Solution With Number of Defining Respondents $(n=152)$

\begin{tabular}{lccc}
\hline Characteristic & Factor 1 & Factor 2 & Total \\
\hline Number of Definers & 88 & 52 & 140 \\
Eigenvalue & 38.25 & 19.89 & \\
Percent of Variation Explained & 25 & 13 & 38 \\
\hline
\end{tabular}




\section{Defining Respondents}

Table 5 also shows the number of defining respondents for each factor.

Participants strongly loaded on a given factor are considered to be definers of that specific factor who are assumed to share a common perspective (McKeown \& Thomas, 1988). Only the responses from the definers of a factor are used to calculate and explain the characteristics of that given factor (e.g., eigenvalue and percentage of explained variance). In other words, the percentage of explained variation on each factor is the variance accounted for by the definers of a given factor. In this study, 140 out of 152 respondents were loaded strongly on Factors 1 and 2, thus defining these factors.

The PQMethod program output automatically gives correlation coefficients representing factor loadings for each respondent on each type (see Appendix A). The correlation coefficient scores followed by an " $\mathrm{X}$ " indicate that the corresponding participants loaded strongly on that factor, and thus partially defined that type. The factor loadings indicate how similar definers are to the underlying factor characteristics. The higher the correlation coefficient, the more similarity a definer shares with the underlying type.

The two factors were moderately correlated. The result of this study showed that undergraduate respondents tended to share some study behaviors, which creates a moderate level of correlation between the factors $(r=.519)$ This moderate correlation 
could be explained by several consensus statement items that existed in the data and are discussed in the "consensus statements" section, below.

\section{Factor Scores}

In order to understand and interpret each factor type, the researcher examined the factor scores of each instrument item for each factor type. Factor scores are the main basis for factor interpretation. A factor score for a statement item is an average of the scores given to that statement by all the definers on that factor. PQMethod automatically normalizes factor scores, which are essentially weighted z-scores for each item on the instrument. A table of the all the items and factor scores for each item on each factor can be found in Appendices B and C. The items that have positive z-scores are considered to load positively on a factor. Those which have negative z-scores are considered to load negatively on a factor.

The factor scores on statement items are used to establish factor arrays for each factor. The statements (i.e., items on the SBI) with the highest factor scores are given the highest ranking in the array (Addams \& Proops, 2000). These factor arrays help factor interpretation as they represent the significant patterns embodied in the data. Three main categories of data are used to characterize a type. These are statements with extreme rankings, distinguishing statements, and consensus statements. 
Statements with extreme rankings. Statements with extreme rankings are the ones with the highest and lowest z-scores. These statements are found at both ends of the original instrument scales. The current study used the conventional cutoff values of z-scores for extreme rankings. That is, statements with $z$-scores of +1 or greater and -1 or less were considered the statements with extreme rankings. Statements ranked at the extremes in the factor array are the most important as they strongly define the type. That is, extreme z-scored statements indicate the characteristics respondents feel most strongly describe their study behavioral patterns. It is important to note that a negative z-score does not necessarily indicate a negative study behavior. Rather, when a negative score is given to a negatively phrased statement, the behavior expressed in the statement is actually supported. For instance, statement 19: "I watch too much television, and this interferes with my studies" is a negative study behavior. A negative ranking (i.e., a negative z-score) on this statement indicates students' effective time management for studying. Each statement has to be examined, individually and collectively, to understand the characteristics each Q factor represents.

Distinguishing statements and consensus statements. In addition to extreme ranked statements, distinguishing statements also help the researcher to interpret salient features of a given type. Distinguishing items are the statements that differentiate a given factor the most from the other factors. In this study, statements with a z-score 
difference of 1 or greater are considered distinguishing statements. Distinguishing items show what is unique about a given factor. On the other side, statements with a $\mathrm{z}$-score difference of less than 1 are considered consensus statements (Barry \& Proops, 2000). They illustrate the study behaviors held in common among all types of respondents. The following section details the characteristics of two factors by looking at extreme ranked statements, distinguishing statements and consensus statements.

\section{Factors with Extreme Statements}

Factor 1. Factor 1 had 88, the greatest number, of respondents highly loaded on it.

Factor 1 accounted for $25 \%$ of the total observed variance in the data (as noted above in Table 5). The factor array for Factor 1 in descending orders of statements can be found in Appendix B. The statement items of the extreme ranking positions, designated by extreme z-scores in Factor 1 are shown in Table 6.

Factor 1 was largely characterized by study behaviors that were reflective and well-organized. This type of student learns in a holistic way by connecting study materials and seeking the underlying structures that made sense to them (agreement with Statements 5 and 37).

Additionally, Type 1 students manage their time effectively (agreement with Statements 40, 4, 9, and disagreement with Statement 39) and do not let non-academic activities interfere with their studying (disagreement with Statement 19). 
Table 6

Factor 1 Extreme Statements With High and Low z-scores

\begin{tabular}{|c|c|c|}
\hline No. & Statement & Z-score \\
\hline 11 & $\begin{array}{l}\text { In preparing reports, themes, term papers, etc., I make certain that } \\
\text { I clearly understand what is wanted before I begin to work. }\end{array}$ & 1.867 \\
\hline 4 & I complete my homework assignments on time. & 1.765 \\
\hline 40 & $\begin{array}{l}\text { If time is available, I take a few minutes to check over my } \\
\text { answers before turning in my examination paper. }\end{array}$ & 1.692 \\
\hline 30 & $\begin{array}{l}\text { I keep all the notes for each subject together carefully arranging } \\
\text { them in some logical order. }\end{array}$ & 1.463 \\
\hline 26 & $\begin{array}{l}\text { When in doubt about the proper form for a written report, } \\
\text { I refer to an approved model to provide a guide to follow. }\end{array}$ & 1.388 \\
\hline 5 & $\begin{array}{l}\text { I try to carry over and relate material learned in one course to that } \\
\text { learned in others. }\end{array}$ & 1.357 \\
\hline 7 & $\begin{array}{l}\text { I keep my assignments up-to-date by doing my work regularly } \\
\text { from day to day. }\end{array}$ & 1.353 \\
\hline 37 & $\begin{array}{l}\text { When preparing for an examination, I learn facts in some logical } \\
\text { order of importance, order of presentation in class or textbook, } \\
\text { order in history, etc. }\end{array}$ & 1.336 \\
\hline 9 & $\begin{array}{l}\text { At the beginning of a study period, I organize my work so that I } \\
\text { will utilize the time more effectively. }\end{array}$ & 1.256 \\
\hline 19 & I watch too much television, and this interferes with my studies. & -1.140 \\
\hline 39 & $\begin{array}{l}\text { Although I work until the last possible minute, I am unable to } \\
\text { finish examination within the allotted time. }\end{array}$ & -1.142 \\
\hline 14 & $\begin{array}{l}\text { My teacher criticizes my written reports as being hastily } \\
\text { written or poorly organized. }\end{array}$ & -1.175 \\
\hline 33 & $\begin{array}{l}\text { I do poorly on tests because I find it hard to think clearly and plan } \\
\text { my work when I am faced with an exam. }\end{array}$ & -1.181 \\
\hline 38 & $\begin{array}{l}\text { I am careless with spelling and mechanics of English } \\
\text { composition when answering examination questions. }\end{array}$ & -1.194 \\
\hline
\end{tabular}

Factor 2. Factor 2 had 52 respondents highly loaded on it. This factor accounted for $13 \%$ of the variance in the data (as noted above in Table 5). The factor array for factor 2 in descending orders of statements can be found in Appendix C. The statement 
items of the extreme ranking positions, designated by extreme z-scores in factor 2 are

shown in Table 7.

Table 7

Factor 2 Extreme Statements With High and Low z-scores

\begin{tabular}{clr} 
No. & \multicolumn{1}{c}{ Statement } & Z-score \\
\hline 4 & I complete my homework assignments on time. & 1.872 \\
40 & If time is available, I take a few minutes to check over my & 1.709 \\
& $\begin{array}{l}\text { answers before turning in my examination paper. } \\
26\end{array}$ & $\begin{array}{l}\text { When in doubt about the proper form for a written report, } \\
\end{array}$ \\
I refer to an approved model to provide a guide to follow. & 1.609 \\
44 & I study harder for final exams than for the rest of my coursework. & 1.562
\end{tabular}

43 I believe that grades are based upon a student's ability to 1.527 memorize facts rather than upon the ability to "think things through".

11 In preparing reports, themes, term papers, etc., I make certain that $\quad 1.519$ I clearly understand what is wanted before I begin to work.

1 My time is unwisely distributed; I spend too much time on some things and not enough on others.

16 My studying is done in a random, unplanned manner impelled $\quad 1.188$ mostly by the demands of approaching classes.

18 I put off writing themes, reports, term papers, etc., until the 1.053 last minute.

10 When I am having difficulty with my schoolwork I try to talk $\quad-1.346$ over the trouble with my teacher.

38 I am careless with spelling and mechanics of English $\quad-1.378$ composition when answering examination questions.

31 Before attending class, I prepare by reading or studying the $\quad-1.400$ assignment.

39 Although I work until the last possible minute, I am unable to $\quad-1.585$ finish examination within the allotted time.

29 After a class lecture, I go back and recite to myself the material $\quad-1.687$ in my notes - rechecking points I found doubtful.

14 My teacher criticizes my written reports as being hastily written or poorly organized. 
Students falling into this type are poorly organized about their studying (disagreement with Statement 29 and 31). Although Type 2 students complete their assignment on time, they manage their time poorly (agreement with Statement 1), and appear to procrastinate (agreement with Statement 16 and 18). Additionally, since they procrastinate, Type 2 students usually need to cram for tests and focus on remembering facts rather than comprehending materials and carrying out deep thinking due to time constraints (agreement with Statement 44 and 43). Several statements are scored similarly by both types of students and are discussed in the consensus statements section.

\section{Distinguishing Statements}

In addition to the statements with extreme ranked z-scores, distinguishing statements provide additional information for the researcher. Because there are only two factors in the current study, the distinguishing statements for each type have the z-scores with great distances from each other. Table 8 shows the distinguishing statements based on the z-score differences between two factors. Some distinguishing statements reinforced the interpretation of extreme ranked statements. Specifically, Type 1 students are good organizers concerning both learning materials and their time (agreement with Statements 7, 9, and 27). 
Table 8

Distinguishing Statements for Factor 1 and Factor 2 (or Descending Array of

Difference Between Factor 1 and Factor 2)

No. Statement F1 F2 Difference

\begin{tabular}{|c|c|c|c|c|}
\hline & & Z-score & Z-score & \\
\hline 10 & $\begin{array}{l}\text { When I am having difficulty with my school } \\
\text { work I try to talk over the trouble with my } \\
\text { teacher. }\end{array}$ & 0.87 & -1.35 & 2.22 \\
\hline 7 & $\begin{array}{l}\text { I keep my assignments up-to-date by doing } \\
\text { my work regularly from day to day. }\end{array}$ & 1.35 & -0.56 & 1.91 \\
\hline 31 & $\begin{array}{l}\text { Before attending class, I prepare by reading } \\
\text { or studying the assignment. }\end{array}$ & 0.22 & -1.40 & 1.62 \\
\hline 9 & $\begin{array}{l}\text { At the beginning of a study period, I } \\
\text { organize my work so that I will utilize } \\
\text { the time more effectively. }\end{array}$ & 1.26 & -0.35 & 1.61 \\
\hline 29 & $\begin{array}{l}\text { After a class lecture, I go back and recite to } \\
\text { myself the material in my notes } \\
\text { - rechecking points I found doubtful. }\end{array}$ & -0.25 & -1.69 & 1.44 \\
\hline 27 & $\begin{array}{l}\text { When reading a long textbook assignment, I } \\
\text { stop periodically and mentally review the } \\
\text { main points that have been presented. }\end{array}$ & 1.04 & -0.18 & 1.22 \\
\hline 12 & $\begin{array}{l}\text { When I get behind in my schoolwork for } \\
\text { some unavoidable reason, I make up } \\
\text { back assignments without prompting } \\
\text { from the teacher. }\end{array}$ & 0.88 & -0.14 & 1.02 \\
\hline 44 & $\begin{array}{l}\text { I study harder for final exams than for the } \\
\text { rest of my coursework. }\end{array}$ & -0.08 & 1.56 & -1.64 \\
\hline 1 & $\begin{array}{l}\text { My time is unwisely distributed; I spend } \\
\text { too much time on some things and not } \\
\text { enough on others. }\end{array}$ & -0.49 & 1.19 & -1.68 \\
\hline 18 & $\begin{array}{l}\text { I put off writing themes, reports, term } \\
\text { papers, etc., until the last minute. }\end{array}$ & -0.72 & 1.05 & -1.77 \\
\hline 16 & $\begin{array}{l}\text { My studying is done in a random, } \\
\text { unplanned manner impelled mostly } \\
\text { by the demands of approaching classes. }\end{array}$ & -0.68 & 1.19 & -1.87 \\
\hline 43 & $\begin{array}{l}\text { I believe that grades are based upon a } \\
\text { student's ability to memorize facts rather } \\
\text { than upon the ability to "think things through". }\end{array}$ & -0.39 & 1.53 & -1.92 \\
\hline
\end{tabular}


Equally important, some distinguishing statements offered additional information about the type characteristics. Type 1 students appeared to be active learners who took initiatives of their studying in spite of the obstacles (agreement with Statements 10 and 12). Considering both extreme ranked statements and distinguishing statements, Type 1 students can be labeled "Proactive Learners with Well-Organized Study Behaviors".

As for Type 2 students, distinguishing statements suggested that these students are poorly organized in terms of both learning materials and time (agreement with Statement 1, and disagreement with Statements 7, 31, and 29). They also procrastinate while studying and cram for assignments and tests as deadlines approach (agreement with Statements 44, 18, and 16). Additionally, Type 2 students lack help-seeking behaviors (disagreement with Statement 10). Type 2 students can be labeled "Disorganized Procrastinators".

\section{Consensus Statements}

Consensus statements are the statements scored similarly by all types of participants. Consensus statements in this study informed the researcher that the study behaviors represented by these statements were shared by both types of students. Table 9 shows the consensus statements for both factors. 
Table 9

Consensus Statements for Factor 1 and Factor 2

\begin{tabular}{|c|c|c|c|}
\hline No. & Statement & $\begin{array}{c}\text { F1 } \\
\text { Z-score }\end{array}$ & $\begin{array}{c}\mathrm{F} 2 \\
\mathrm{z} \text {-score }\end{array}$ \\
\hline $2 *$ & $\begin{array}{l}\text { I find it hard to force myself to finish work by a } \\
\text { certain time; work is unfinished, inferior, or not on time. }\end{array}$ & -1.13 & -1.00 \\
\hline $4^{*}$ & I complete my homework assignments on time. & 1.77 & 1.87 \\
\hline $8^{*}$ & I prefer to study alone rather than with others. & 0.76 & 0.63 \\
\hline $13^{*}$ & $\begin{array}{l}\text { Difficulty in expressing myself in writing slows me } \\
\text { down on reports, themes, examinations, and other work } \\
\text { to be turned in. }\end{array}$ & -0.85 & -0.77 \\
\hline $20 *$ & I work too many hours for the course load I am carrying. & -0.68 & -0.67 \\
\hline $21^{*}$ & $\begin{array}{l}\text { Personal problems with my family affect my ability } \\
\text { to concentrate on studying. }\end{array}$ & -0.84 & -0.98 \\
\hline 24 & $\begin{array}{l}\text { I skip over the figures, graphs, and tables in a reading } \\
\text { assignment. }\end{array}$ & -0.83 & -0.65 \\
\hline 26 & $\begin{array}{l}\text { When in doubt about the proper form for a written report, } \\
\text { I refer to an approved model to provide a guide to follow. }\end{array}$ & 1.39 & 1.61 \\
\hline $28 *$ & $\begin{array}{l}\text { When writing down notes from a lecture, I have trouble } \\
\text { picking out the important points. I tend to put down } \\
\text { material that turns out to be unimportant. }\end{array}$ & -0.84 & -0.80 \\
\hline 38 & $\begin{array}{l}\text { I am careless with spelling and mechanics of English } \\
\text { composition when answering examination questions }\end{array}$ & -1.19 & -1.38 \\
\hline $40 *$ & $\begin{array}{l}\text { If time is available, I take a few minutes to check over } \\
\text { my answers before turning in my examination paper. }\end{array}$ & 1.69 & 1.71 \\
\hline
\end{tabular}

Note. All listed statements do not show significantly different z-scores between Types I and II at $p=.01$, and those flagged with an $*$ are also non-significant at $p=.05$.

Several consensus statements indicated that both types of students slightly prefer studying independently than with others. These same students disagree with the notion they have difficulties in expressing their ideas or writing in English. Interestingly, these students also agreed they finished their academic work on time. As the findings have shown, Type 1 and Type 2 students took very different approaches to managing their time for studying; therefore, it would be helpful to examine the actual academic 
achievement from these two types of students. Understanding how these two types of study behaviors relate to students' academic outcomes would in turn inform the researchers about the difference that students' study behaviors make.

\section{Correlation of Study Behavior Types with Academic Achievement}

The second research question in this study was whether the student type based on study behaviors is related to students' academic achievement measured by students' self-reported current GPAs. As mentioned above, in the Q factor analysis, 140 participants in total highly loaded on and thus defined Factor 1 or Factor 2. Among these 140 participants, seven did not report current GPA, one missed enrollment status, and one missed age. The final regression analysis was based on 131 cases, with 80 students in Type 1group and 51 students in Type 2 group.

The researcher first hypothesized that students' type is related to their current grade point averages (GPA) at the .05 level of significance. In order to test the hypothesis, an independent-samples $t$ test was conducted by using students' self-reported current GPAs as the dependent variable, and student type as the independent variable. Table 10 displays the results of the $t$-test of the null hypothesis that the mean GPAs of Type 1 group and Type 2 group were equal. It was found that Type 1 students had significantly higher average GPAs $(M=3.350, S D=.372)$ than Type 2 students $(M=3.178, S D=$ 
.538). The $t$-test value is $t(129)=2.165, p=.016$. The difference has a moderate effect size of $d=.388$.

Table 10

t-Test for Differences in GPA by Student Type

\begin{tabular}{cccccc}
\hline & & & & \multicolumn{2}{c}{$95 \%$ CI } \\
\cline { 3 - 6 } & $t$ & $d f$ & $p$ & $L L$ & $U L$ \\
\hline GPA & 2.165 & 129 & .016 & .01489 & .3310 \\
\hline \multicolumn{2}{l}{ Note. CI = confidence interval; $\mathrm{LL}=$ lower limit; $\mathrm{UL}=$ upper limit. }
\end{tabular}

A hierarchical regression procedure was further employed to estimate the unique contribution of student type to the variance of GPA when student attributes were controlled. The results of the hierarchical multiple regression analyses are shown in Table 11. The first step of the regression analysis, or Model 1, tested whether four attributes, (i.e., sex, age, major, and enrollment status) would predict academic achievement as measured by GPA. The combination of sex, age, major, and enrollment status was found to significantly predict academic achievement, $R^{2}=.150, F(6,124)=$ $3.656, p<.005$, and accounted for a total of $15.0 \%$ of the variance of academic achievement. Among the attribute variables, sex $(\beta=.318, t=2.294)$, STEM major $(\beta$ $=-.511, t=-3.524)$, and business major $(\beta=-.224, t=-2.230)$ emerged as significant predictors of academic achievement.

In the second step of the analysis, or Model 2, the researcher added the student type (i.e., study behavior type) as an independent variable. The purpose was to evaluate the 
potential predictive ability of study behavior type on academic achievement when controlling for sex, age, major, enrollment status. Model 2 with the combination of sex, age, major, enrollment status, and student type was significantly related to academic achievement, $R^{2}=.177, F(7,123)=3.771, p<.001$, and accounted for a total of $17.7 \%$ of the variance of academic achievement. More importantly, the significant increase in $R^{2}\left[\Delta R^{2}=.026, F(1,123)=3.938, p<.05\right]$ showed that the student type added significant incremental variance to the first model. Student type was a significant predictor of academic achievement beyond and above the four attributes $(\beta=.167, t=1.985)$, and accounted for $2.6 \%$ of the variance of academic achievement.

In the third step of the analysis, or Model 3, in order to determine whether or not student type interacted with sex, age, major, or enrollment status in predicting students' academic achievement, four interaction terms were added (i.e., type $\times$ age, type $\times$ sex, type $\times$ major, and type $\times$ enrollment status). The $5.7 \%$ increase in $R^{2}$ was non-significant $(p>.05)$. Interaction variables did not add significant incremental variance to the second model and thus did not contribute to the prediction of academic achievement. In particular, all interaction terms were non-significant $(p>.05)$. In other words, students' sex, age, major, and enrollment status did not interact with their study behavior types in predicting academic achievement. 
Table 11

Hierarchical Multiple Regression Analyses Predicting GPA From

Student type, Sex, Age, Major, and Enrollment Status

\begin{tabular}{|c|c|c|}
\hline Predictor & $\Delta R^{2}$ & $\beta$ \\
\hline Step 1 & $.150 * *$ & \\
\hline Sex & & $.318^{*}$ \\
\hline Age & & -.018 \\
\hline STEM & & $-.511 * * *$ \\
\hline Business & & $-.224 *$ \\
\hline Other Major & & -.153 \\
\hline Enrollment status & & $.180^{*}$ \\
\hline Step 2 & $.026^{*}$ & \\
\hline Type & & $.167^{*}$ \\
\hline Step 3 & .057 & \\
\hline Type $\times$ Sex & & .412 \\
\hline Type $\times$ Age & & 1.041 \\
\hline Type $\times$ STEM & & -.089 \\
\hline Type $\times$ Business & & -.256 \\
\hline Type $\times$ Other Major & & .092 \\
\hline Type $\times$ Enrollment Status & & -.015 \\
\hline Total $R^{2}$ & .234 & \\
\hline$n$ & 131 & \\
\hline
\end{tabular}

A Q factor analysis using principal component extraction with varimax rotation was used in this study. The analysis yielded a two factor structure providing a stable and interpretable description of student types based on study behaviors. The two factor solution included $91.5 \%$ of the participants and accounted for $38 \%$ of the total variance. Factor 1 describes students who organize both their time and learning materials well. Type 1 students also show reflective and proactive behaviors during their studies. Type 
1 students are labeled "Proactive Learners with Well-Organized Study Behaviors".

Factor 2 describes students who have poor organization in terms of both their learning materials and time. Additionally, Type 2 students are highly likely to procrastinate and cram as deadlines approach. Type 2 students are labeled "Disorganized Procrastinators".

The result of an independent-samples $t$ test showed significant differences between the mean GPAs of the Type 1 and Type 2 students at the .05 significance level. Student characteristics including sex, age, major, and enrollment status were significant in predicting academic achievement as measured by GPA. Furthermore, student type was a significant predictor of academic achievement beyond and above students' characteristics. Student type made a unique contribution in predicting academic achievement when students' characteristics were controlled. No interaction was found between student characteristics and type in predicting academic achievement. 


\section{CHAPTER V}

\section{DISCUSSION AND RECOMMENDATION}

This chapter presents a summary of the current study, a discussion of the findings, and recommendations based on these findings. This study aimed to better understand study behaviors of university undergraduate students. Specifically, the study was first designed to determine how undergraduate students could be grouped into different types based on their self-reported study behaviors. Second, it was designed to examine whether the student types, if they exist, are related to academic achievement as measured by students' self-reported current GPAs.

One hundred fifty two undergraduate students voluntarily participated in the current study by completing the Study Behavior Inventory instrument. All participants were enrolled in fall semester of 2010 at Florida International University. The data were Q factor analyzed and the results showed that the participants divided into two response types (Q factors) based on their study behaviors. The first student type (i.e., Factor 1) describes proactive learners who organize both their study materials and study time well. The second type (i.e., Factor 2) describes students who are poorly organized and also procrastinate. The results of regression analyses showed that Type 1 students' average GPAs were significantly higher than that of Type 2 students. Student type made a 
unique and significant contribution in predicting students' GPAs beyond and above attribute variables including sex, age, major, and enrollment status.

\section{Discussion of the Findings}

Students' academic outcomes are important for measuring success of both individual students and universities. Researchers have suggested that study behaviors are one of the key personal factors that influence academic outcomes. Appropriate study behaviors are believed to contribute to students' academic success in colleges (Bandura, 2001; Zimmerman, 2008). Examining students' study behaviors is essential in understanding how types of study behaviors predict academic outcomes, as well as providing guidance on how to improve them, which contributes to better academic performance.

The current study has several theoretical implications. This study looked at study behaviors through self-regulated learning theory. Self-regulated learning theory explains what learners do as they perform successfully academically. According to the theorists (Pintrich \& Zusho, 2007; Zimmerman, 1998), self-regulation is a multilevel mechanism that learners utilize to direct their own learning process and accomplish academic goals. Self-regulated students actively regulate their motivation, thoughts, and behaviors during the learning process by taking environmental cues and feedback into consideration and adapting their behavior appropriately. Students who execute self-regulated learning well are more likely to have high academic achievement (Pajares, 
2008; Pintrich \& Zusho, 2007; Zimmerman, 2000a). Based on self-regulated learning theory, students who use appropriate study behaviors are expected to perform better academically then those who do not.

The two significant types of study behaviors found in the current study largely support previous research on learning behaviors and their relationship with academic achievement. This study found two typical student types based on study behaviors among college undergraduate students. The findings also showed significant differences in GPAs between students in these two study behavioral types. Participants who define (i.e., who load highly on) Type 1 organize their learning purposefully, manage their time effectively, and perform better academically. By contrast, Type 2 students organize their learning poorly, if at all, procrastinate in their academic work, and have lower academic achievement. These findings are in line with self-regulated learning theory. That is, students who consistently regulate their learning endeavors tend to have better academic outcomes than those who hardly regulate their study behaviors.

One feature that contrasts the two types of students the most in the current study is how they process the academic materials in order to learn. Type 1 students were found to learn in a holistic way by connecting study materials and seeking the underlying structure or relationship that made sense to them. Related to this, they generally 
believed that "thinking things through" is more important than memorizing plain facts in their academic study. In contrast, Type 2 students considered remembering facts more important in order to acquire high course grades and tended to not actively attempt to relate the academic contents and understand the logic behind them. Clearly, having meaningful understanding and thinking critically about the content being taught is what matters most to high-achieving students, but tends to matter less to lower-achieving, Type 2 students.

This is a unique finding of the current study. In a previous study done by McDermott (2004), item 43 on the SBI instrument that reads, "I believe that grades are based upon a student's ability to memorize facts rather than upon the ability to 'think things through"' did not function appropriately. In her study, this item provided inconsistent scores and failed to load on any of the factors. Therefore, she suggested removing this item from the instrument. However, in the current study, item 43 has the most extreme negative z-score between the two student factors. In other words, one thing that particularly differentiates the two types of students is how they approach the academic work - do they barely memorize the facts and surface information or do they go through deep thinking to understand the materials, concepts, and the meaning or logic behind them? 
Several theories could be used to explain such different behavioral patterns. One of them is goal orientation within the self-regulated learning theory. Goal orientation in academic settings refers to the reasons why individuals pursue an academic task.

Students' goal orientations largely determine their motivations behind academic learning and achievement, which in turn influences the efforts and behaviors they demonstrate in their learning process.

Researchers have proposed different models of goal orientations (see Pintrich, 2000), but most models include two types of goals concerning the purposes of individuals' involvement in a task. The first goal orientation is labeled mastery/ learning goal orientation (Ames, 1992; Dweck \& Leggett, 1988). Learners with mastery or learning goals focus on learning new knowledge and skills, increasing their competence, gaining deep understanding and mastering tasks (Ames, 1992; Anderman \& Midgley, 1997; Dweck \& Leggett, 1988; Pintrich, 2000). The second type of goal orientation is labeled performance goal orientation, which involves avoiding negative judgment (e.g., getting lower grades or looking stupid) and/or outperforming peers (Ames, 1992; Dweck \& Leggett, 1988).

Empirical studies have repeatedly found positive relationships between mastery goals and self-regulation of learning, including the three factors underlying the Study Behavior Inventory. For example, when students set their academic goals to be learning 
and improving themselves, they actively engage in self-regulatory processes of learning (Pintrich \& Schunk, 1996). Students who report using mastery goals are highly likely to monitor their cognition and behaviors to enhance understanding and comprehension as they study (Pintrich \& Zusho, 2007). These students have been found to maintain their self-efficacy (i.e., the first factor of the SBI) and to be able to adapt their learning strategies and behaviors when facing obstacles (Dweck \& Leggett, 1988). Mastery goals are also positively related to students' management of time and effort - the second and the third factors underlying the SBI (Pintrich, 2000).

On the other hand, the relationship between performance goals and self-regulation of learning is more complicated (see Pintrich, 2000). But many researchers agree that students who hold performance goals to avoid negative judgment often demonstrate poor self-regulatory processes and learning outcomes (Middleton \& Midgley, 1997; Skaalvik, 1997). Such students are less likely to devote enough time and effort to pursue deep understanding (Pintrich, 2000). The reason behind this is that if they have low academic performance, these students could attribute it to either (a) their poor study behaviors such as not devoting adequate time and effort or (b) simply their lack of competence and ability to perform the academic tasks. By blaming "not trying hard enough" for the poor performance, these students could avoid looking incompetent and therefore protect their 
own self-image and self-confidence. This is known as the self-worth protection mechanism (see Covington, 1992).

Consistent with this literature, the current study found that two types of students behave differently in the ways they approach academic tasks. Type 1, high-achieving students pay more attention to the deep understanding of meaning and logic behind the materials being taught, whereas Type 2, lower-achieving students focus more on surface information and facts. This could be due to the different types of academic goals students set as they pursue tasks. That is, Type 1 students are likely to be mastery goal orientated and Type 2 students to be performance goal oriented. Additionally, members of Type 1, the high-achieving student type, tend to plan ahead, monitor their progress and understanding, and regulate their study time and effort. This is consistent with the previous literature on mastery goal orientation.

Another theory that can explain the different types of learning behaviors and the corresponding differences on academic outcomes is Bloom's Taxonomy of the Cognitive Domain (Bloom, 1956). Bloom clarified six levels of development of intellectual skills within the cognitive domain: (a) knowledge, (b) comprehension, (c) application, (d) analysis, (e) synthesis, and (f) evaluation. These six levels follow a hierarchical order from the simplest (i.e., knowledge) to the most complex (i.e., evaluation). One needs to master the first level in order to move onto the next level. The simplest, the knowledge 
level, focuses on memorizing and recalling information (e.g., facts, terms, and basic concepts) previously learned. This is what Type 2 students reported doing in the current study. According to Bloom, at this lowest level, knowledge acquisition and learning is superficial.

By contrast, at the higher levels of the taxonomy, for example synthesis, students not only have to comprehended and interpreted the knowledge, but also compare, contrast, and analyze in order to connect or distinguish the structure of a given issue or topic. Again, this is very similar to the learning behaviors that Type 1 students reported in the current study. Theory suggests and empirical research has shown that students who learn a topic at the higher levels of the taxonomy have better knowledge retention and comprehension than those who learn at the lower levels of the taxonomy (Garavalia, Hummel, Wiley, \& Huitt, 1999; Wong \& Day, 2009).

In sum, the differences found between two types of students on how to approach knowledge could be understood through Bloom's Taxonomy of the cognitive domain. High achieving students are likely to focus on higher levels of the taxonomy - for example, analyzing and making connections between different pieces of information, comprehending and building their own structure of knowledge - thus, acquiring meaningful understanding and critical thinking and performing well academically. Low-achieving students instead rely mainly on remembering the basic facts, terms, and 
formulas, which leads to superficial understanding of the knowledge being taught.

Unsurprisingly, these students are less likely to perform adequately in their learning.

Another characteristic that strongly differentiates the two types of students in this study was the students' responses to item 10 of the SBI, which probes students' help-seeking behaviors. Type 1/high-achieving students tend to seek help when it is needed whereas Type 2, low-achieving students, are reluctant to do so. Self-regulated learning theorists have considered seeking help and feedback critical as it not only helps change the way students think, feel, and behave as they learn, but the valuable information provided by teachers or peers may also facilitate students' learning (Pintrich $\&$ Zusho, 2007). The current findings supported the idea that self-regulated learners are more likely to be aware of their need to seek help and more willing to seek help than their underperforming peers.

The current study also showed that Type 1/high-achieving students schedule their academic work ahead in a productive manner; while Type 2 students usually study in a random fashion and are rarely involved in planning for their study, be it preparation in advance or review after class. Similarly, literature has suggested that students' active engagement in planning and organizing is related to high performance in various academic tasks (Pintrich \& De Groot, 1990; Whipp \& Chiarelli 2004). Achievement increases as students take greater control over their own learning. 
Type 1 students characterize themselves as spending plenty of time on academic assignments and not letting non-academic activities interfere with their studying. By contrast, Type 2 students spend more time on entertainment and other non-academic related activities. Previous research has shown that students who are better at allocating and prioritizing their time tend to have higher achievement than their peers who manage time poorly (Eilam \& Aharon, 2003; Ogonor \& Nwadiani, 2006). This study again demonstrates that devoting an adequate amount of time to study activities is related to satisfactory academic performance, especially in college and university given its loosely structured environment.

A further thing that differentiates the two types of students is whether they spend time on their studying on a regular basis. As the findings have shown, Type 2 students usually start working on their assignments or papers as deadlines approach rather than starting early and spending time regularly on them as Type 1 students do. One of the explanations behind this behavior is that many believe they are more productive under pressure, such as that imposed by limited time, which was partly supported by Chu and Choi's (2005) findings. However, most of the literature suggests the opposite; that is, dividing up work systematically and spending time on it regularly is more likely to yield satisfactory performances and outcomes (Garcia-Ros et al., 2004; George et al., 2008). By the same token, failing to regulate one's time usage effectively (e.g., procrastination) 
usually leads to all kinds of negative outcomes, such as the need for cramming, high stress levels, and overall low academic performance (Ferrari, 2001; Steel, 2007). It is reasonable to suggest that devoting an adequate amount of time to academic-related activities outside of class regularly is necessary for academic success (Nonis \& Hudson, 2006).

This study also found that high-achieving (i.e., Type 1) students are more likely to check and reflect on the academic activities they are engaged in than Type 2 students. Bandura, Zimmerman, and other researchers of self-regulated learning theory all agree on the critical role of students' self-monitoring in improving their learning quality and academic outcomes (Pintrich \& Zusho, 2007; Zimmerman, 2000a; Zimmerman \& Bandura, 1994). Students who regularly involve themselves in self-checking and monitoring tend to be acutely aware of the progress (or lack of it) that they made in academic activities and regulate their own studying correspondingly (Kanfer, 1971). From this study, it appears such study behaviors indeed turn out to be conducive to academic achievement, as the literature has suggested.

\section{Recommendations for Future Research and Practice}

This study is an exploratory study by revealing various types of undergraduate students regarding their study behavior patterns and describing in details each study 
behavioral types held by those students through Q factor analysis. A few recommendations could be followed for future research and practice.

\section{Research Recommendations}

In the current study, $\mathrm{Q}$ factor analysis was carried out on the responses from a sample of 152 university undergraduate students. The researcher reexamined the data with a varimax rotation and selected a two-factor structure which provided the most stable and interpretable description of participant types. Yet, literature has suggested that Q factor analysis, like any other kind of factor analysis, tends to be sample-specific.

Future research should examine the same question using different samples in order to determine whether the two-factor structure found in the current study is replicable in different university student samples. If a two-factor structure is found, future studies should also examine whether a similar relationship between student type and academic achievement will reemerge.

Another reason to replicate the study using different samples is related to the effect size. In the current study, the correlation between study behavioral type and academic achievement was statistically significant. However, the effect size of predictor variable type was fairly small $\left(R^{2}=.026\right)$. Several researchers (e.g., Newman \& Newman, 2000) have argued that while a large $R^{2}$ is preferable, a small $\mathrm{R}^{2}$ could be meaningful if the effect size is consistently reliable. The reason is because a small increase of effect size 
would improve predictive efficiency, and if the small $R^{2}$ is replicable, the predictor can have huge effects over time (Newman and Newman, 2000). An appropriate example used by Newman and Newman was the odds ratio at casinos. The roulette tables usually give the house a slight advantage for each play. Yet over a long run, that small advantage/effect generates billions of dollars for the house as it is consistent over time. Therefore, future research should use different samples to examine whether student type would yield similar effect size in predicting academic achievement. Considering the sheer size of the entire population of university/college undergraduate students, a small $R^{2}$ of the type variable that replicates over different samples would potentially impact a large number of undergraduates' learning behaviors and outcomes.

The current study concluded that the study behavioral type is significantly related to academic achievement, which is a correlational statement. In order to be able to make a causal statement about the relationship between behavioral type and academic achievement, experimental research on this topic is needed. For example, as mentioned in the "practical implication" section, one action that educators and institutions can take is to provide training on effective study behaviors for Type 2 students -- Disorganized Procrastinators. In order to examine the causal relationship between study behaviors and academic achievement, researchers could use experimental design to test whether acquiring effective study behaviors (through intervention) will lead to better academic 
performance. Cuesta (2007) found a causal relationship between acquiring appropriate study behaviors and increased academic achievement in college remedial mathematics classes, but more research is needed on regular non-remedial student populations. If a causal relationship is ultimately found in regular students, training programs on the acquisition and application of effective study behaviors should be widely implemented in colleges and/or universities.

When using experimental design, researchers should also pay attention to the potential relationship of sex and study behavior types as well as of sex and academic performance. The current study found that men and women do not differ in study behavioral types, but male participants showed significantly higher average GPA than their female peers. The literature has been inconclusive on this issue so far. Bliss and his colleagues (Bliss \& Muller, 1993; Bliss \& Sandiford, 2004) didn’t find differences of sex on self-regulatory study behaviors while others did (McDermott, 2004; Wilberg \& Lynn, 1999). Therefore, it will be informative to examine whether and how males and females differ on study behavioral types in experimental studies.

This study found out that what differentiates Type 1 and Type 2 students the most is their attitudes about the usefulness of higher-level thinking. The high-achieving, Type 1 students believe critical thinking and gaining deep understanding of the content matters most to them. Type 2, lower-achieving students focus more on memorizing mere facts. 
Based on this correlational study, I can state that as a predictor variable, students' attitude about the usefulness of higher-level thinking is significantly related to the outcome variable academic achievement. Yet in order to make a causal statement, future research is needed. Future experimental study should be conducted to determine whether there is a causal relationship between students' attitude about the usefulness of higher-level thinking and academic achievement. Based on Cuesta's (2007) findings, it is very likely that using higher-order thinking more frequently will lead to better academic outcomes.

Besides, the Study Behavior Inventory has only a few statement items that directly or indirectly measure students' attitudes and usages of higher-order thinking. An instrument should be developed to measure students' attitudes about and/or frequency of using higher-level thinking. Such instrument could be used to examine the predictability of students' attitudes and usages of higher-level thinking on academic achievement.

\section{Practical Implications}

The findings from the current study have provided both students and educators with valuable information concerning students' study behavior patterns. Some measure of students' study behaviors should be implemented as soon as students enter higher educational institutions. The results of such measurement will inform students about the 
strengths and weaknesses in their learning habits as well as the potential academic performances associated with them. As self-regulation literature has repeatedly suggested, self-awareness is critical for students to direct and regulate their own learning practices (Pintrich \& Zusho, 2007; Zimmerman, 1998). Based on the feedback about the strengths and weaknesses in their study habits, students should be able to adjust study behaviors that are not productive or to continue learning behaviors and processes that are conducive to academic success (Zimmerman, 2000a).

Furthermore, understanding students' learning behavior patterns allows educators to pay special attentions to the group of students who demonstrate ineffective study behaviors and habits, such as poor time management, procrastination, and lack of preparation in and review of the course contents. Since study behavioral patterns are very likely to be associated with poor academic performance, as found in the current study and the literature (Eilam \& Aharon, 2003; George et al., 2008; Whipp \& Chiarelli 2004), knowledge of these patterns could help identify students who are at risk for academic failure. If future research finds a causal relationship between study behavioral patterns and academic achievement, educators can help these students to learn in a more effective way by tailoring instructional methods to increase students' academic performance. For example, educators could pose questions involving higher-level thinking, which requires students to engage in learning behaviors at the higher levels of 
the taxonomy (Bloom, 1956). Similarly, by using ongoing authentic assessment, instructors would help students practice reviewing of the course contents and self-monitoring of comprehension on a frequent basis. In addition, long-term projects and research paper are the common types of assignments in colleges. Instead of simply asking students to submit at the end of semesters, instructors could divide it into multiple sub-sections and set a timetable for completing each sub-section. This would help students, especially those who are disorganized, to better plan and manage their time for academic work. By using different methods, educators are able to provide "scaffoldings" for students who lack effective learning behaviors and facilitate them study better.

At the institutional level, colleges and universities should provide training in the development and application of the effective study behaviors as part of the first year experience programs. Cuesta (2007) has demonstrated that study behaviors can be taught to college students, which led to both more effective study behaviors and better academic performance. Such training programs could target students' weaknesses and allow them to practice effective learning behaviors until they eventually internalize these newly learned behaviors. By acquiring effective learning behaviors early on in college, students are more likely to stay in college, make adequate academic progress, and graduate in a timely fashion. 


\section{Conclusion}

Study behaviors and habits are important because what students are actually doing contributes to their academic performances. This study examined study behaviors from a different approach by using $\mathrm{Q}$ factor analysis. Essentially, the study examined the study behaviors of students and placed them into categories or "types" based on these responses so that members of a given group shared similar study behavior patterns. Self-regulation theorists (e.g., Bandura, 1986; Pintrich \& Zusho, 2007; Zimmerman, 2000a) have suggested that individuals direct their learning processes in different ways as they engage in academic tasks. Some students actively regulate their thoughts, behaviors, and motivations during learning process while others do poorly in directing and monitoring their own learning processes. Self-regulated learners generally perform better academically then those who fail to self-regulate their learning.

From this study, it appears that college undergraduate students emerged in two profiles representing two distinctive patterns of study behaviors. The type is correlated with students' academic outcomes in that students in the two types showed significant differences in their mean GPAs. This study provides an opportunity for examining what students actually do from their own accounts and could allow educators to potentially tailor their instructional practices leading to better outcomes for both individual students and educational institutions. 


\section{REFERENCES}

Addams, H., \& Proops, J. (Eds.). (2000). Social discourse and environmental policy: An application of $Q$ methodology. Cheltenham, UK: Edward Elgar.

Ames, C. (1992). Classrooms: Goals, structures, and student motivation. Journal of Educational Psychology, 84, 261-271.

Anderman, E., \& Midgley, C. (1997). Changes in achievement goal orientations, perceived academic competence and grades across the transition to middle-level schools. Contemporary Educational Psychology, 22, 269-298.

Baker, L., \& Brown, A. L. (1984). Metacognitive skills and reading. In P. D. Pearson (Ed.), Handbook of reading research (pp. 353-394). New York, NY: Longman.

Balduf, M. (2009). Underachievement among college students. Journal of Advanced Academics, 20, 274-294.

Bandura, A. (1977). Self-efficacy: Toward a unifying theory of behavioral change. Psychological Review, 84, 191-215.

Bandura, A. (1986). Social foundations of thought and action: A social cognitive theory. Englewood Cliffs, NJ: Prentice Hall.

Bandura, A. (1997). Self-efficacy: The exercise of control. New York, NY: Freeman.

Bandura, A. (2001). Social cognitive theory: An agentic perspective. Annual Review of Psychology, 52, 1-26.

Bliss, L. B., Kerstiens, G., \& Marvin, R. (2000). The Study Behavior Inventory (Version 2.0). Torrance, CA: Androgogy Associates.

Bliss, L. B., \& Mueller, R. J. (1987). Assessing study behaviors of college students: Findings from a new instrument. Journal of Developmental Education, 11(2), 14-18.

Bliss, L. B., \& Mueller, R .J. (1993). An instrument for the assessment of study behaviors of college students. Reading Research and Instruction, 32(4), 46-52. 
Bliss, L. B., \& Sandiford, J. R. (2004). Linking study behaviors and student culture to academic success among Hispanic students. Community College Journal of Research and Practice, 28, 281-295.

Bloom, B. S. (1956). Taxonomy of educational objectives, Handbook I: The cognitive domain. New York, NY: David McKay,

Boekaerts, M., Pintrich, P. R., \& Zeidner, M. (2000). Handbook of self-regulation: Theory, research, and applications. New York, NY: Academic Press.

Britton, B. K., \& Tesser, A. (1991). Effects of time-management practices on college grades. Journal of Educational Psychology, 83, 405-410.

Brown, L. D. (1986). Q technique and method: Principles and procedures. In W. D. Berry \& M. S. Lewis-Beck (Eds.), New tools for social scientists (pp. 57-76). Beverly Hills, CA: Sage.

Brown, L. D. (1991). Bridging organizations and sustainable development. Human Resources, 44, 807-831.

Brown, L. D. (1993). A primer on Q methodology. Operant Subjectivity, 16, 91-138.

Brown, R. D., \& Pirtle, T. (2008). Beliefs of professional and family caregivers about the sexuality of individuals with intellectual disabilities: Examining beliefs using a Q-methodology approach. Sex Education: Sexuality, Society and Learning, 8, 59-75.

Brown, S. R. (1971). The forced-free distinction in Q-technique. Journal of Educational Measurement, 8, 283-287.

Brown, S. R. (1980). Political subjectivity: Applications of $Q$ methodology in political science. New Haven: Yale University Press.

Brown, S. R. (2010a, February 1). Saturation, et al. Message posted to Q method electronic mailing list. To retrieve, send electronic message "get q-method $\log 1002$ " addressed to listserv@listserv.kent.edu. The access is restricted to listserv members. Join via http://qmethod.org/issss.php, following "Q Listserv Instructions". 
Brown, S. R. (2010b, February 5). C Cross-validation, et al. Message posted to Q method electronic mailing list. To retrieve, send electronic message "get q-method $\log 1002$ " addressed to listserv@listserv.kent.edu. The access is restricted to listserv members. Join via http://qmethod.org/issss.php, following "Q Listserv Instructions".

Burt, C. (1972). The reciprocity principle. In S. R. Brown \& D. J. Brenner (Eds.), Science, psychology, and communication: Essays honoring William Stephenson (pp. 39-56). New York, NY: Teachers College Press.

Camahalan, F. M. G. (2006). Effects of self-regulated learning on mathematics achievement of selected Southeast Asian children. Journal of Instructional Psychology, 33, 194-205.

Caprara, G. V., \& Cervone, D. (2000). Personality: Determinants, dynamics, and potentials. Cambridge, UK: Cambridge University Press.

Cattell, R. B. (1978). The scientific use of factor analysis in behavioral and life sciences. New York, NY: Plenum.

Chong, W. H. (2007). The role of personal agency beliefs in academic self-regulation: An Asian perspective. School Psychology International, 28, 63-76.

Chu A. H. C., \& Choi, J. N. (2005). Rethinking procrastination: Positive effects of "active" procrastination behavior on attitudes and performance. The Journal of Social Psychology, 145, 245-263.

Collins, J. L. (1982, March). Self-efficacy and ability in achievement behavior. Paper presented at the annual meeting of the American Educational Research Association, New York, NY.

Covington, M. V. (1992). Making the grade: A self-worth perspective on motivation and school reform. Cambridge, UK: Cambridge University Press.

Cuesta, Z. M. (2007). The effect of instruction on the study behaviors and academic achievement of community college students. ProQuest ETD Collection for FIU. Paper AAI3268644. http://digitalcommons.fiu.edu/dissertations/AAI3268644 
Dembo, M. H., \& Eaton, M. J. (2000). Self-regulation of academic learning in middle-level schools. The Elementary School Journal, 100, 473-490.

Dweck, C. S., \& Leggett, E. L. (1988). A social-cognitive approach to motivation and personality. Psychological Review, 95, 256-273.

Dewitte, S., \& Schouwenburg, H. C. (2002). Procrastination, temptations, and incentives: The struggle between the present and the future in procrastinators and the punctual. European Journal of Personality, 16, $469-489$.

Dinsmore, D. L., Alexander, P. A., \& Loughlin, S. M. (2008). Focusing the conceptual lens on metacognition, self-regulation, and self-regulated learning. Educational Psychology Review, 20, 391-409.

Eilam, B., \& Aharon, I. (2003). Students' planning in the process of self-regulated learning. Contemporary Educational Psychology, 28, 304-334.

Ferrari, J. R. (2001). Procrastination as self-regulation failure of performance: Effects of cognitive load, self-awareness and time limits on 'working best under pressure'. European Journal of Personality, 15, 391-406.

Flavell, J. H. (1971). First discussant's comments: What is memory development the development of? Human Development, 14, 272-278.

Flavell, J. H. (1976) Metacognitive aspects of problem solving. In L. B. Resnick (Ed.), The nature of intelligence (pp. 231-236). Hillsdale, NJ: Erlbaum.

Flavell, J. H. (1979). Metacognition and cognitive monitoring: A new area of cognitive-developmental inquiry. American Psychologist, 34, 906-1011.

Florida International University: About FIU. (n.d.). Retrieved January 8, 2010, from http://www.fiu.edu/docs/about_fiu.htm

Fritzsche, B. A., Young, B. R., \& Hickson, K. C. (2003). Individual differences in academic procrastination tendency and writing success. Personality and Individual Differences, 35, 1549-1557. 
Galayda, J. (2006). Community supported agriculture, economic preference theory and subjective well-being. (Doctoral dissertation, Rensselaer Polytechnic Institute, 2006) Proquest Dissertations \& Theses. (AAT 3232608).

Garavalia, L., Hummel, J., Wiley, L., \& Huitt, W. (1999). Constructing the course syllabus: Faculty and student perceptions of important syllabus components. Journal of Excellence in College Teaching, 10, 5-22.

Garcia-Ros, R., Perez-Gonzalez, F., \& Hinojosa, E. (2004). Assessing time management skills as an important aspect of student learning: The construction and evaluation of a time management scale with Spanish high school students. School Psychology International, 25, 167-183.

George, D., Dixon, S., Stansal, E., Gelb, S. L., \& Pheri, T. (2008). Time diary and questionnaire assessment of factors associated with academic and personal success among university undergraduates. Journal of American College Health, 56, 706-715.

Goldfinch, J., \& Hughes, M. (2007). Skills, learning styles and success of first-year undergraduates. Active Learning in Higher Education, 8, 259-273.

Holder, B. (2007). An investigation of hope, academics, environment, and motivation as predictors of persistence in higher education online programs. Internet and Higher Education, 10, 245-260.

Jain, S., \& Dowson, M. (2009). Mathematics anxiety as a function of multidimensional self-regulation and self-efficacy. Contemporary Educational Psychology, 34, 240-249.

Jakubowski, T. G., \& Dembo, M. H. (2002, April). Social cognitive factors associated with the academic self-regulation of undergraduate college students in a learning and study strategies course. Paper presented at the annual meeting of the American Educational Research Association, New Orleans, LA. Retrieved from ERIC database. (ED465335)

Jones, C. H., Slate, J. R., Perez, E., \& Marini, I. (1996). Graduate students'study skills as a function of academic achievement, sex, conceptions of intelligence, and locus of control. New Directions for Education Reform, 3, 61-78. 
Kanfer, F. H. (1971). The maintenance of behavior by self-generated stimuli and reinforcement. In A. Jacobs \& L. B. Sachs (Eds.), The psychology of private events (pp. 398-416). New York, NY: Academic Press.

Kitsantas, A. (2002). Test preparation and performance: A self-regulatory analysis. Journal of Experimental Education, 70, 101-113.

Kitsantas, A., Winsler, A., \& Huie, F. (2008). Self-regulation and ability predictors of academic success during college: A predictive validity study. Journal of Advanced Academics, 20, 42-68.

Lahmers, A. G., \& Zulauf, C. R. (2001). Factors associated with academic time use and academic performance of college students: A recursive approach. Journal of College Student Development, 41, 544-556.

Lindblom-Ylanne, S. (2004). Raising students' awareness of their approaches to study. Innovations in Education and Teaching International, 41, 405-421.

McDermott, M. A. (2004). The validation of an instrument for the assessment of study behaviors of high school students. ProQuest ETD Collection for FIU. Paper AAI3165165. http://digitalcommons.fiu.edu/dissertations/AAI3165165

McKeown, M., Hinks, M., Stowell-Smith, M., Mercer, D., \& Forster, J. (1999). Q methodology, risk management, and quality management. International Journal of Health Care Quality Assurance, 12, 254-266.

McKeown, B., \& Thomas, D. B. (1988). Q methodology. (Quantitative Applications in the Social Sciences, Vol. 66.). Newbury Park, CA: Sage.

Middleton, M., \& Midgley, C. (1997). Avoiding the demonstration of lack of ability: An underexplored aspect of goal theory. Journal of Educational Psychology, 89, 710-718.

National Center for Education Statistics (2004a). Indicator 18: Remediation and degree completion. Washington, DC: NCES. Retrieved February 5, 2010, from http://nces.ed.gov/programs/coe/2004/section3/indicator18.asp 
National Center for Education Statistics. (2004b). Indicator 19: Trends in undergraduate persistence and completion. Washington, DC: NCES. Retrieved February 5, 2010, from http://nces.ed.gov/programs/coe/2004/ section3/indicator19.asp

Newman, I., \& Newman, C. (2000). A discussion of low R-squares: Concerns and uses. Educational Research Quarterly, 24(2), 3-9.

Newman, I., \& Ramlo, S. E. (2010). The use of two multivariate techniques, Q methodology and $\mathrm{Q}$ factor analysis, to facilitate interpretation of mixed methods research. In C. Teddlie \& A. Tashakkori (Eds.), Handbook of mixed methods in social and behavioral research (pp.505-530). Thousand Oaks, CA: Sage.

Niemczyk, M. C., \& Savenye, W. C. (2001, Nov). The relationship of student motivation and self-regulated learning strategies to performance in an undergraduate computer literacy course. Annual Proceedings of Selected Research and Development Papers Presented at the National Convention of the Association for Educational Communications and Technology, Atlanta, Georgia. Retrieved from ERIC database. (ED740107)

Nonis, S. A., \& Hudson, G. I. (2006). Academic performance of college students: Influence of time spent studying and working. Journal of Education for Business, $81,151-159$.

Ogonor, B. O., \& Nwadiani, M. (2006). An analysis of non-instructional time management of undergraduates in southern Nigeria. College Student Journal, 40, 204-217.

Pajares, F. (1996). Self-efficacy beliefs in academic settings. Review of Educational Research, 66, 543-578.

Pajares, F. (2002). Gender and perceived self-efficacy in self-regulated learning. Theory into Practice, 41, 116-125.

Pajares, F. (2008). Motivational role of self-efficacy beliefs in self-regulated learning. In D. H. Schunk \& B. J. Zimmerman (Eds.), Motivation and self-regulated learning: Theory, research and applications (pp. 111-139). New York: Lawrence Erlbaum Associates. 
Pajares, F., Britner, S. L., \& Valiante, G. (2000). Relation between achievement goals and self-beliefs of middle school students in writing and science. Contemporary Educational Psychology 25, 406-422.

Pajares, F., \& Graham, L. (1999). Self-efficacy, motivation constructs, and mathematics performance of entering middle school students. Contemporary Educational Psychology, 24, 124-139.

Pintrich, P. (2000). The role of goal orientation in self-regulated learning. In M. Boekaerts, P. Pintrich, \& M. Zeidner (Eds.), Handbook of self-regulation (pp. 452-501). San Diego, CA: Academic Press.

Pintrich, P., \& De Groot, E. V. (1990). Motivational and self-regulated learning components of classroom academic performance. Journal of Educational Psychology, 82, 33-40.

Pintrich, P., \& Schunk, D. H. (1996). Motivation in education: Theory, research and applications. Englewood Cliffs, NJ: Prentice Hall Merrill.

Pintrich, P., \& Zusho, A. (2007). Student motivation and self-regulated learning in the college classroom. In R. Perry \& J. C. Smart (Eds.), The scholarship of teaching and learning in higher education: An evidence-based perspective (pp. 731-810). New York, NY: Springer.

Reder, L. Y., \& Schunn, C. D. (1996). Metacognition does not imply awareness: Strategy choice is governed by implicit learning and memory. In L. Y. Reder (Ed.), Implicit memory and metacognition. Mahah, NJ: Erlbaum.

Schmolck, P. (May 13, 2011). QMethod Page. Retrieved from http://www.lrz.de/ $\sim$ schmolck/qmethod/\#PQMethod

Schouwenburg, H. C., \& Groenewoud, J. T. (2001). Study motivation under social temptation: Effects of trait procrastination. Personality and Individual Differences, 30, 229-240.

Schraw, G., Crippen, K. J., \& Hartley, K. (2006). Promoting self-regulation in science education: Metacognition as part of a broader perspective on learning. Research in Science Education, 36, 111-139. 
Schunk, D. H. (2008) Metacognition, self-regulation, and self-regulated learning: Research recommendations. Educational Psychology Review, 20, 463-467.

Schunk, D. H., \& Zimmerman, B. J. (1994). Self-regulation in education: Retrospect and prospect. In D. H. Schunk \& B. J. Zimmerman (Eds.), Self-regulation of learning and performance and educational applications (pp. 305-314). Hillsdale, NJ: Lawrence Erlbaum Associates.

Schunk, D. H., \& Zimmerman, B. J. (2006). Competence and control beliefs: Distinguishing the means and ends. In P. A. Alexander \& P. H. Winne (Eds.), Handbook of educational psychology (2nd ed., pp. 349-367). Mahwah, NJ: Lawrence Erlbaum Associates.

Skaalvik, E. (1997). Self-enhancing and self-defeating ego orientation: Relations with task avoidance orientation, achievement, self-perceptions, and anxiety. Journal of Educational Psychology, 89, 71-81.

Smith, N. W. (2001). Current systems in psychology: History, theory, research, and applications. Belmont, CA: Wadsworth/Thompson Learning.

Steel, P. (2007). The nature of procrastination: A meta-analytic and theoretical review of quintessential self-regulatory failure. Psychological Bulletin, 133, 65-94.

Stephenson, W. (1967). The play theory of mass communication. Chicago: University of Chicago Press.

Stephenson, W. (1975). The study of behavior: Q-technique and its methodology. Chicago: University of Chicago Press.

Tuckman, B. W. (2002, August). Academic procrastinators: Their rationalizations and web-course performance. Paper presented at the annual meeting of the American Psychological Association, Chicago, IL. Retrieved from ERIC database. (ED470567)

Weiner, B. (1995). Judgments of responsibility: A foundation for a theory of social conduct. New York: Guilford Press. 
Whipp, J. L., \& Chiarelli, S. (2004). Self-regulation in a web-based course: A case study. Educational Technology Research and Development, 52(4), 5-22.

Wilberg, S., \& Lynn, R. (1999). Sex differences in historical knowledge and school grades: A 26 nation study, Personality and Individual Differences, 27, 1221-1229.

Wigfield, A. (1994). Expectancy-value theory of achievement motivation: A developmental perspective. Educational Psychology Review, 6, 49-78.

Wilson, N. L. F. (2002). Russian consumer attitudes toward American advertising. (Doctoral dissertation) Retrieved from Proquest Dissertations and Theses database (UMI No. 3074456)

Witkow, M. R. (2009). Academic achievement and adolescents' daily time use in the social and academic domains. Journal of Research on Adolescence, 19, 151-172.

Wolters, C. A. (2003). Understanding procrastination from a self-regulated learning perspective. Journal of Educational Psychology, 95, 179-187.

Wong, K. K. H., \& Day, J. R. (2009). A comparative study of problem-based and lecture-based learning in junior secondary school science. Research in Science Education, 39, 625-642.

Young, M. R., Klemz, B. R., \& Murphy, W. J. (2003). Enhancing learning outcomes: The effects of instructional technology, learning styles, instructional methods, and student behavior. Journal of Marketing Education, 25, 130-142.

Yumusak, N., Sungur, S., \& Cakiroglu, J. (2007). Turkish high school students' biology achievement in relation to academic self-regulation. Educational Research and Evaluation, 13, 53-69.

Zimmerman, B. J. (1989). Models of self-regulated learning and academic achievement. In B. J. Zimmerman \& D. H. Schunk (Eds.), Self-regulated learning and academic achievement: Theory, research, and practice (pp. 1-25). New York, NY: Springer-Verlag.

Zimmerman, B. J. (1998). Academic studying and the development of personal skill: A self-regulatory perspective. Educational Psychologist, 33, 73-86. 
Zimmerman, B. J. (2000a). Attaining self-regulation: A social cognitive perspective. In M. Boekaerts, P. R. Pintrich, \& M. Zeidner (Eds.), Handbook of self-regulation: Theory, research, and applications (pp. 13-39). New York, NY: Academic Press.

Zimmerman, B. J. (2000b). Self-efficacy: An essential motive to learn. Contemporary Educational Psychology, 25, 82-91.

Zimmerman, B. J. (2001). Theories of self-regulated learning and academic achievement: An overview and analysis. In B. J. Zimmerman \& D. H. Schunk (Eds.), Self-regulated learning and academic achievement: Theoretical perspectives (pp. 1-37). Mahwah, NJ: Erlbaum Associates.

Zimmerman, B. J. (2008). Investigating self-regulation and motivation: Historical background, methodological developments, and future prospects. American Educational Research Journal, 45, 166-183.

Zimmerman, B. J., \& Bandura, A. (1994). Impact of self-regulatory influences on writing course attainment. American Educational Research Journal, 31, 845-862.

Zimmerman, B. J., Bandura, A., \& Martinez-Pons, M. (1992). Self-motivation for academic attainment: The role of self-efficacy beliefs and personal goal setting. American Educational Research Journal, 29, 663-676.

Zimmerman, B. J., \& Kitsantas, A. (1997). Developmental phases in self-regulation: Shifting from process goals to outcome goals. Journal of Educational Psychology, 89, 29-36.

Zimmerman, B. J., \& Kitsantas, A. (1999). Acquiring writing revision skill: Shifting from process to outcome self-regulatory goals. Journal of Educational Psychology, 91, 241-250. 
APPENDICES 
APPENDIX A

Participants' Factor Loadings on each factor with an X Indicating a Defining Participant

\begin{tabular}{|c|c|c|c|c|c|}
\hline Participant & Factor 1 & Factor 2 & Participant & Factor 1 & Factor 2 \\
\hline 1 & 0.3280 & $0.4419 \mathrm{X}$ & 34 & -0.2297 & $0.5836 \mathrm{X}$ \\
\hline 2 & $-0.3396 X$ & -0.0037 & 35 & -0.0981 & 0.0100 \\
\hline 3 & 0.0480 & $0.5181 X$ & 36 & $0.4672 \mathrm{X}$ & 0.2341 \\
\hline 4 & $0.3640 X$ & 0.2598 & 37 & $0.4699 \mathrm{X}$ & 0.3613 \\
\hline 5 & $0.6928 \mathrm{X}$ & 0.3346 & 38 & 0.3383 & $0.4584 X$ \\
\hline 6 & -0.2341 & $0.5606 \mathrm{X}$ & 39 & $0.6769 X$ & -0.0429 \\
\hline 7 & $0.3314 \mathrm{X}$ & 0.0584 & 40 & -0.0678 & $0.3437 \mathrm{X}$ \\
\hline 8 & 0.3471 & $0.4819 \mathrm{X}$ & 41 & -0.0548 & $0.6965 X$ \\
\hline 9 & 0.3955 & $0.6780 \mathrm{X}$ & 42 & $0.5780 \mathrm{X}$ & 0.3276 \\
\hline 10 & 0.3047 & $0.4252 \mathrm{X}$ & 43 & $0.7206 \mathrm{X}$ & 0.2856 \\
\hline 11 & 0.3895 & $0.4779 X$ & 44 & 0.3200 & $0.5628 \mathrm{X}$ \\
\hline 12 & -0.1257 & $0.2950 \mathrm{X}$ & 45 & -0.0153 & 0.1615 \\
\hline 13 & -0.1177 & $0.5844 X$ & 46 & $0.3548 \mathrm{X}$ & 0.3425 \\
\hline 14 & $0.8607 \mathrm{X}$ & 0.1173 & 47 & 0.2925 & $0.4884 X$ \\
\hline 15 & 0.1460 & 0.1920 & 48 & 0.3597 & $0.5288 \mathrm{X}$ \\
\hline 16 & 0.4551 & $0.4973 \mathrm{X}$ & 49 & $0.4456 \mathrm{X}$ & 0.4187 \\
\hline 17 & $0.6068 X$ & 0.3576 & 50 & $0.5855 X$ & 0.2297 \\
\hline 18 & $0.4345 \mathrm{X}$ & 0.2076 & 51 & 0.4584 & $0.5874 X$ \\
\hline 19 & $0.3923 \mathrm{X}$ & 0.2294 & 52 & 0.3871 & $0.4206 \mathrm{X}$ \\
\hline 20 & 0.2523 & $0.6150 \mathrm{X}$ & 53 & $0.7490 \mathrm{X}$ & 0.0893 \\
\hline 21 & 0.2110 & $0.5330 \mathrm{X}$ & 54 & 0.1172 & $0.5361 X$ \\
\hline 22 & 0.2198 & $0.3110 \mathrm{X}$ & 55 & $0.6859 X$ & 0.3832 \\
\hline 23 & 0.2740 & $0.5436 \mathrm{X}$ & 56 & $0.5498 X$ & 0.2564 \\
\hline 24 & $0.5004 X$ & 0.2716 & 57 & $0.8264 X$ & 0.1342 \\
\hline 25 & 0.0792 & $0.6499 X$ & 58 & 0.0026 & $0.5362 X$ \\
\hline 26 & $0.6086 \mathrm{X}$ & 0.3837 & 59 & $0.7446 \mathrm{X}$ & 0.1391 \\
\hline 27 & $0.7049 X$ & 0.1411 & 60 & $0.8399 X$ & -0.0562 \\
\hline 28 & $0.5273 \mathrm{X}$ & 0.3884 & 61 & $0.3615 \mathrm{X}$ & 0.3217 \\
\hline 29 & $0.7362 X$ & -0.0510 & 62 & $0.6601 X$ & -0.0226 \\
\hline 30 & 0.2277 & $0.5433 X$ & 63 & $0.6794 X$ & 0.1563 \\
\hline 31 & 0.0280 & 0.0463 & 64 & $0.6940 \mathrm{X}$ & 0.1258 \\
\hline 32 & 0.4149 & $0.5484 X$ & 65 & 0.0621 & $0.4713 \mathrm{X}$ \\
\hline 33 & $0.5678 \mathrm{X}$ & 0.4130 & 66 & 0.2923 & $0.4268 \mathrm{X}$ \\
\hline
\end{tabular}




\begin{tabular}{|l|l|l|l|l|l|}
\hline 67 & $0.7739 \mathrm{X}$ & 0.2399 & 104 & $0.3377 \mathrm{X}$ & 0.0064 \\
\hline 68 & 0.4609 & $0.5546 \mathrm{X}$ & 105 & $0.5524 \mathrm{X}$ & 0.5326 \\
\hline 69 & $0.6542 \mathrm{X}$ & 0.1426 & 106 & 0.3129 & $0.6048 \mathrm{X}$ \\
\hline 70 & 0.3068 & $0.6268 \mathrm{X}$ & 107 & $0.4809 \mathrm{X}$ & 0.3999 \\
\hline 71 & $0.7835 \mathrm{X}$ & 0.1202 & 108 & 0.4584 & $0.5418 \mathrm{X}$ \\
\hline 72 & $0.9327 \mathrm{X}$ & 0.0903 & 109 & $0.7129 \mathrm{X}$ & 0.1790 \\
\hline 73 & 0.3000 & $0.4180 \mathrm{X}$ & 110 & 0.1068 & $0.4554 \mathrm{X}$ \\
\hline 74 & $0.8663 \mathrm{X}$ & 0.1189 & 111 & 0.2689 & $0.3330 \mathrm{X}$ \\
\hline 75 & -0.3279 & $0.5026 \mathrm{X}$ & 112 & $0.7890 \mathrm{X}$ & 0.2146 \\
\hline 76 & $0.6501 \mathrm{X}$ & 0.2300 & 113 & $0.5396 \mathrm{X}$ & 0.3322 \\
\hline 77 & $0.8042 \mathrm{X}$ & 0.1483 & 114 & $0.3612 \mathrm{X}$ & 0.3126 \\
\hline 78 & $0.6377 \mathrm{X}$ & 0.1790 & 115 & $0.7545 \mathrm{X}$ & -0.1779 \\
\hline 79 & $0.5537 \mathrm{X}$ & 0.4823 & 116 & $0.4072 \mathrm{X}$ & 0.3120 \\
\hline 80 & $0.7416 \mathrm{X}$ & 0.2410 & 117 & -0.0575 & $0.5289 \mathrm{X}$ \\
\hline 81 & $0.4776 \mathrm{X}$ & 0.0020 & 118 & 0.3936 & $0.5064 \mathrm{X}$ \\
\hline 82 & $0.7162 \mathrm{X}$ & 0.3823 & 119 & -0.0150 & 0.2336 \\
\hline 83 & 0.3281 & $0.3648 \mathrm{X}$ & 120 & $0.4396 \mathrm{X}$ & 0.3219 \\
\hline 84 & -0.2777 & 0.2263 & 121 & -0.0287 & $0.3143 \mathrm{X}$ \\
\hline 85 & $0.4535 \mathrm{X}$ & -0.1728 & 122 & $0.6567 \mathrm{X}$ & 0.4846 \\
\hline 86 & $0.6671 \mathrm{X}$ & -0.1515 & 123 & $0.5708 \mathrm{X}$ & 0.3534 \\
\hline 87 & 0.2204 & 0.1550 & 124 & -0.1780 & $0.4568 \mathrm{X}$ \\
\hline 88 & $0.5416 \mathrm{X}$ & 0.4438 & 125 & $0.4473 \mathrm{X}$ & 0.0507 \\
\hline 89 & $0.6717 \mathrm{X}$ & 0.0820 & 126 & $0.5971 \mathrm{X}$ & 0.4678 \\
\hline 90 & -0.1920 & $0.4463 \mathrm{X}$ & 127 & $0.3356 \mathrm{X}$ & 0.2915 \\
\hline 91 & $0.4038 \mathrm{X}$ & 0.3878 & 128 & $0.3824 \mathrm{X}$ & 0.3394 \\
\hline 92 & 0.2813 & $0.4332 \mathrm{X}$ & 129 & 0.0391 & $0.4157 \mathrm{X}$ \\
\hline 93 & $0.6792 \mathrm{X}$ & 0.2592 & 130 & $0.6783 \mathrm{X}$ & 0.1699 \\
\hline 94 & $0.6698 \mathrm{X}$ & 0.2495 & 131 & -0.2467 & -0.0719 \\
\hline 95 & 0.2618 & $0.3465 \mathrm{X}$ & 132 & $0.6443 \mathrm{X}$ & 0.0299 \\
\hline 96 & $0.5375 \mathrm{X}$ & 0.1885 & 133 & $0.3850 \mathrm{X}$ & 0.1458 \\
\hline 97 & 0.1901 & 0.1470 & 134 & 0.2713 & $0.2985 \mathrm{X}$ \\
\hline 98 & $0.4682 \mathrm{X}$ & 0.2697 & 135 & $0.3543 \mathrm{X}$ & 0.2447 \\
\hline 99 & $0.7821 \mathrm{X}$ & 0.0011 & 136 & 0.2083 & $0.3395 \mathrm{X}$ \\
\hline 100 & $0.6568 \mathrm{X}$ & -0.0173 & 137 & $0.4939 \mathrm{X}$ & 0.2242 \\
\hline 101 & $0.4410 \mathrm{X}$ & 0.3746 & 138 & 0.4535 & $0.5403 \mathrm{X}$ \\
\hline 102 & $0.5037 \mathrm{X}$ & 0.2294 & 139 & 0.2964 & $0.4988 \mathrm{X}$ \\
\hline 103 & $0.8416 \mathrm{X}$ & 0.1329 & 140 & $0.6955 \mathrm{X}$ & 0.1703 \\
\hline & & & & & \\
\hline
\end{tabular}




\begin{tabular}{|l|l|l|l|l|l|}
\hline 141 & 0.2542 & 0.2468 & 148 & $0.5111 \mathrm{X}$ & 0.2986 \\
\hline 142 & $-0.3862 \mathrm{X}$ & 0.2485 & 149 & $0.8458 \mathrm{X}$ & -0.0590 \\
\hline 143 & $0.7948 \mathrm{X}$ & -0.2055 & 150 & 0.1376 & 0.1039 \\
\hline 144 & $0.8170 \mathrm{X}$ & -0.0270 & 151 & $0.7978 \mathrm{X}$ & 0.1544 \\
\hline 145 & $0.7007 \mathrm{X}$ & 0.1490 & 152 & -0.1480 & 0.2690 \\
\hline 146 & $0.3274 \mathrm{X}$ & 0.1608 & 153 & 0.1508 & 0.0020 \\
\hline 147 & -0.2337 & $0.5550 \mathrm{X}$ & \multicolumn{3}{l}{} \\
\cline { 1 - 4 }
\end{tabular}


APPENDIX B

Factor Array for Factor/Type 1 with Descending z-scores on Each Statement

\begin{tabular}{|c|c|c|}
\hline No . & Statement & Z-score \\
\hline 11 & $\begin{array}{l}\text { In preparing reports, themes, term papers, etc., I make certain that I } \\
\text { clearly understand what is wanted before I begin to work. }\end{array}$ & 1.867 \\
\hline 4 & I complete my homework assignments on time. & 1.765 \\
\hline 40 & $\begin{array}{l}\text { If time is available, I take a few minutes to check over my answers } \\
\text { before turning in my examination paper. }\end{array}$ & 1.692 \\
\hline 30 & $\begin{array}{l}\text { I keep all the notes for each subject together carefully arranging them } \\
\text { in some logical order. }\end{array}$ & 1.463 \\
\hline 26 & $\begin{array}{l}\text { When in doubt about the proper form for a written report, I refer to an } \\
\text { approved model to provide a guide to follow. }\end{array}$ & 1.388 \\
\hline 5 & $\begin{array}{l}\text { I try to carry over and relate material learned in one course to that } \\
\text { learned in others. }\end{array}$ & 1.357 \\
\hline 7 & $\begin{array}{l}\text { I keep my assignments up-to-date by doing my work regularly from } \\
\text { day to day. }\end{array}$ & 1.353 \\
\hline 37 & $\begin{array}{l}\text { When preparing for an examination, I learn facts in some logical order } \\
\text { of importance, order of presentation in class or textbook, order in } \\
\text { history, etc. }\end{array}$ & 1.336 \\
\hline 9 & $\begin{array}{l}\text { At the beginning of a study period, I organize my work so that I will } \\
\text { utilize the time more effectively. }\end{array}$ & 1.256 \\
\hline 36 & $\begin{array}{l}\text { I plan out in my mind the answer to subjective or essay-type } \\
\text { examination questions before starting to write the answer. }\end{array}$ & 1.085 \\
\hline 27 & $\begin{array}{l}\text { When reading a long textbook assignment, I stop periodically and } \\
\text { mentally review the main points that have been presented. }\end{array}$ & 1.038 \\
\hline 23 & $\begin{array}{l}\text { I try to summarize, classify, and systematize facts learned, associating } \\
\text { them with previously learned materials and facts. }\end{array}$ & 1.005 \\
\hline 12 & $\begin{array}{l}\text { When I get behind in my schoolwork for some unavoidable reason, I } \\
\text { make up back assignments without prompting from the teacher. }\end{array}$ & 0.876 \\
\hline 10 & $\begin{array}{l}\text { When I am having difficulty with my schoolwork I try to talk over the } \\
\text { trouble with my teacher. }\end{array}$ & 0.869 \\
\hline 8 & I prefer to study alone rather than with others. & 0.758 \\
\hline 6 & $\begin{array}{l}\text { I copy the diagrams, drawings, tables, and other illustrations that the } \\
\text { instructor puts on the blackboard. }\end{array}$ & 0.703 \\
\hline 17 & $\begin{array}{l}\text { I try to do some "over-learning" — working beyond the point of } \\
\text { immediate memory or recall. }\end{array}$ & 0.329 \\
\hline
\end{tabular}


I think I would do much better on tests if I could take them alone and/or not feel pressured by a time limit.

31 Before attending class, I prepare by reading or studying the assignment. $\quad 0.223$

44 I study harder for final exams than for the rest of my coursework.

3 With some of my courses I like to study with others.

After a class lecture, I go back and recite to myself the material in my notes - rechecking points I found doubtful.

I believe that grades are based upon a student's ability to memorize facts rather than upon the ability to "think things through".

My time is unwisely distributed; I spend too much time on some things and not enough on others.

I have to re-read material several times - the words don't have much meaning the first time I go over them.

Worry about how well I will do interferes with my preparation and

During an examination, I forget names, dates, formulas, and other details that I really do know.

20 I work too many hours for the course load I am carrying.

My studying is done in a random, unplanned manner impelled mostly by the demands of approaching classes.

41 I put off writing themes, reports, term papers, etc., until the last minute.

$-0.720$ When tests are returned, I find my grade has been lowered because of careless mistakes.

After reading several pages of an assignment, I am unable to recall what I just read.

I lose points on true-false or multiple-choice examinations because I

35 change my original answer only to discover later that I was right the first time.

I get nervous and confused when taking an examination and fail to answer questions to the best of my ability.

24 I skip over the figures, graphs, and tables in a reading assignment.

When writing down notes from a lecture, I have trouble picking out the

28 important points. I tend to put down material that turns out to be unimportant.

Difficulty in expressing myself in writing slows me down on reports, themes, examinations, and other work to be turned in. 
34 I have difficulty in picking out important points of a reading assignment - points that later appear on examinations.

15 I set aside returned examinations, reports, and homework assignments without bothering to correct errors noted by the instructor.

I find it hard to force myself to finish work by a certain time; work is unfinished, inferior, or not on time.

19 I watch too much television, and this interferes with my studies.

39 Although I work until the last possible minute, I am unable to finish examination within the allotted time.

14 My teacher criticizes my written reports as being hastily written or poorly organized.

33 I do poorly on tests because I find it hard to think clearly and plan my work when I am faced with an exam.

38 I am careless with spelling and mechanics of English composition when answering examination questions. 
APPENDIX C

Factor Array for Factor/Type 2 with Descending z-scores on Each Statement

\begin{tabular}{|c|c|c|}
\hline No. & Statement & Z-score \\
\hline 4 & I complete my homework assignments on time. & 1.872 \\
\hline 40 & $\begin{array}{l}\text { If time is available, I take a few minutes to check over my answers before } \\
\text { turning in my examination paper. }\end{array}$ & 1.709 \\
\hline 26 & $\begin{array}{l}\text { When in doubt about the proper form for a written report, I refer to an } \\
\text { approved model to provide a guide to follow. }\end{array}$ & 1.609 \\
\hline 44 & I study harder for final exams than for the rest of my coursework. & 1.562 \\
\hline 43 & $\begin{array}{l}\text { I believe that grades are based upon a student's ability to memorize facts } \\
\text { rather than upon the ability to "think things through". }\end{array}$ & 1.527 \\
\hline 11 & $\begin{array}{l}\text { In preparing reports, themes, term papers, etc., I make certain that I clearly } \\
\text { understand what is wanted before I begin to work. }\end{array}$ & 1.519 \\
\hline 1 & $\begin{array}{l}\text { My time is unwisely distributed; I spend too much time on some things } \\
\text { and not enough on others. }\end{array}$ & 1.190 \\
\hline 16 & $\begin{array}{l}\text { My studying is done in a random, unplanned manner impelled mostly by } \\
\text { the demands of approaching classes. }\end{array}$ & 1.188 \\
\hline 18 & I put off writing themes, reports, term papers, etc., until the last minute. & 1.053 \\
\hline 30 & $\begin{array}{l}\text { I keep all the notes for each subject together carefully arranging them in } \\
\text { some logical order. }\end{array}$ & 0.886 \\
\hline 45 & $\begin{array}{l}\text { I think I would do much better on tests if I could take them alone and/or } \\
\text { not feel pressured by a time limit. }\end{array}$ & 0.880 \\
\hline 37 & $\begin{array}{l}\text { When preparing for an examination, I learn facts in some logical order of } \\
\text { importance, order of presentation in class or textbook, order in history, } \\
\text { etc. }\end{array}$ & 0.819 \\
\hline 5 & $\begin{array}{l}\text { I try to carry over and relate material learned in one course to that learned } \\
\text { in others. }\end{array}$ & 0.799 \\
\hline 36 & $\begin{array}{l}\text { I plan out in my mind the answer to subjective or essay-type examination } \\
\text { questions before starting to write the answer. }\end{array}$ & 0.678 \\
\hline 8 & I prefer to study alone rather than with others. & 0.629 \\
\hline 41 & $\begin{array}{l}\text { When tests are returned, I find my grade has been lowered because of } \\
\text { careless mistakes. }\end{array}$ & 0.342 \\
\hline 6 & $\begin{array}{l}\text { I copy the diagrams, drawings, tables, and other illustrations that the } \\
\text { instructor puts on the blackboard. }\end{array}$ & 0.327 \\
\hline 46 & $\begin{array}{l}\text { Worry about how well I will do interferes with my preparation and } \\
\text { performance on tests. }\end{array}$ & 0.278 \\
\hline
\end{tabular}


I try to summarize, classify, and systematize facts learned, associating them with previously learned materials and facts.

I have to re-read material several times - the words don't have much meaning the first time I go over them.

During an examination, I forget names, dates, formulas, and other details that I really do know.

When I get behind in my schoolwork for some unavoidable reason, I make up back assignments without prompting from the teacher.

When reading a long textbook assignment, I stop periodically and mentally review the main points that have been presented.

I lose points on true-false or multiple-choice examinations because I

35 change my original answer only to discover later that I was right the first time.

19 I watch too much television, and this interferes with my studies. I get nervous and confused when taking an examination and fail to answer questions to the best of my ability. After reading several pages of an assignment, I am unable to recall what I just read.

At the beginning of a study period, I organize my work so that I will utilize the time more effectively. I have difficulty in picking out important points of a reading assignment points that later appear on examinations.

3 With some of my courses I like to study with others. immediate memory or recall. I keep my assignments up-to-date by doing my work regularly from day to day.

I set aside returned examinations, reports, and homework assignments without bothering to correct errors noted by the instructor.

24 I skip over the figures, graphs, and tables in a reading assignment.

20 I work too many hours for the course load I am carrying. I do poorly on tests because I find it hard to think clearly and plan my work when I am faced with an exam. Difficulty in expressing myself in writing slows me down on reports, themes, examinations, and other work to be turned in. When writing down notes from a lecture, I have trouble picking out the

28 important points. I tend to put down material that turns out to be unimportant. 
Personal problems with my family affect my ability to concentrate on studying.

I find it hard to force myself to finish work by a certain time; work is unfinished, inferior, or not on time.

When I am having difficulty with my schoolwork I try to talk over the trouble with my teacher.

I am careless with spelling and mechanics of English composition when answering examination questions.

31 Before attending class, I prepare by reading or studying the assignment. $\quad-1.400$ Although I work until the last possible minute, I am unable to finish examination within the allotted time.

After a class lecture, I go back and recite to myself the material in my notes - rechecking points I found doubtful.

My teacher criticizes my written reports as being hastily written or poorly organized. 
VITA

\section{YANG YANG}

Born, Nanjing, China

2005

B.A. Advertising and Mass Communication

Nanjing University

Nanjing, China

2006

M.Ed. Curriculum and Instruction

Salem International University

Salem, West Virginia

2011

Doctoral Candidate in Curriculum and Instruction

Florida International University

Miami, Florida 